\title{
The pathophysiology of restricted repetitive behavior
}

\author{
Mark Lewis • Soo-Jeong Kim
}

Received: 12 January 2009 / Accepted: 19 May 2009 /Published online: 16 June 2009

(C) Springer Science + Business Media, LLC 2009

\begin{abstract}
Restricted, repetitive behaviors (RRBs) are heterogeneous ranging from stereotypic body movements to rituals to restricted interests. RRBs are most strongly associated with autism but occur in a number of other clinical disorders as well as in typical development. There does not seem to be a category of RRB that is unique or specific to autism and RRB does not seem to be robustly correlated with specific cognitive, sensory or motor abnormalities in autism. Despite its clinical significance, little is known about the pathophysiology of RRB. Both clinical and animal models studies link repetitive behaviors to genetic mutations and a number of specific genetic syndromes have RRBs as part of the clinical phenotype. Genetic risk factors may interact with experiential factors resulting in the extremes in repetitive behavior phenotypic expression that characterize autism. Few studies of individuals with autism have correlated MRI findings and RRBs and no attempt has been made to associate RRB and postmortem tissue findings. Available clinical and animal models data indicate functional and structural alterations in cortical-basal ganglia circuitry in the expression of RRB, however. Our own studies point to reduced activity of the indirect basal ganglia pathway being associated with high levels of repetitive behavior in an animal model. These findings, if generalizable, suggest specific therapeutic targets. These, and perhaps other, perturbations to cortical basal ganglia circuitry are mediated by specific molecular mechanisms (e.g., altered gene expression) that result in long-term, experience-dependent neuroadaptations that initiate and maintain repetitive behavior. A great deal more
\end{abstract}

M. Lewis $(\bowtie) \cdot$ S.-J. Kim

University of Florida,

Gainesville, FL, USA

e-mail: marklewis@ufl.edu research is needed to uncover such mechanisms. Work in areas such as substance abuse, OCD, Tourette syndrome, Parkinson's disease, and dementias promise to provide findings critical for identifying neurobiological mechanisms relevant to RRB in autism. Moreover, basic research in areas such as birdsong, habit formation, and procedural learning may provide additional, much needed clues. Understanding the pathophysioloy of repetitive behavior will be critical to identifying novel therapeutic targets and strategies for individuals with autism.

Keywords Autism · Neurodevelopmental disorders . Stereotypy · Compulsions · Rituals ·

Cortical-basal ganglia circuitry

\section{Phenomenology of repetitive behavior}

Repetitive behavior refers to a broad class of responses characterized by their repetition, rigidity or inflexibility, and frequent lack of obvious function. Repetitive behaviors described in individuals with autism spectrum disorders (ASD) include stereotyped motor movements, repetitive manipulation of objects, repetitive self-injurious behavior, specific object attachments, compulsions, rituals and routines, an insistence on sameness, repetitive use of language, and narrow and circumscribed interests [1, 2]. Turner [2] conceptualized these various categories of restricted repetitive behaviors (RRB) as falling into two clusters: "lowerorder" motor actions (stereotyped movements, repetitive manipulation of objects) that are characterized by repetition of movement, and more complex or "higher-order" behaviors (compulsions, rituals, insistence on sameness, and circumscribed interests) that have a distinct cognitive component characterized by an adherence to some rule or 
mental set (e.g., needing to have things "just so") and reflect rigidity or inflexibility (Fig. 1) [1-3]. Factor analyses [4, 5] using relevant items from the Autism Diagnostic InterviewRevised (ADI-R) have supported this categorization yielding two factors: repetitive sensory motor behavior and resistance to change/insistence on sameness. Indeed, a recent factor analysis of the structure of the autism symptom phenotype yielded three factors or domains, two of which involved repetitive behavior (inflexible language and behavior, and repetitive sensory and motor behavior) whereas the third factor was social-communication [6]. Lam et al. [7] replicated these two repetitive behavior factors but also found evidence for a third factor that they termed circumscribed interests.

\section{RRB in other disorders}

$\mathrm{RRB}$ is a common feature of a number of other neurodevelopmental disorders with (e.g., Rett, Fragile X, PraderWilli syndromes) or without an identifiable genetic defect. In some cases, these neurodevelopmental disorders include expression of other autistic traits or autistic-like behavior (e.g., Fragile X). In other cases, such as idiopathic intellectual and developmental disability, there is less phenomenological overlap with autism [8]. Moreover, RRBs are also part of the phenotype of other CNS disorders including obsessive-compulsive disorder, Tourette syndrome, schizophrenia, and fronto-temporal and Alzheimer's dementia [9-12]. Other conditions including congenital blindness [13] and early social impoverishment [14, 15] are also associated with aberrant repetitive behavior. This shared phenomenology over a number of clinical disorders and conditions has important implications and challenges for identifying pathophysiological mechanisms of RRB in autism. The most obvious implication is that repetitive behavior likely arises from multiple etiologies or sources of CNS insult. Another obvious implication is that such behavior, given its complexity and heterogeneity, is mediated by complex circuitry which can be dysregulated

\section{Restricted Repetitive Behavior in Neurodevelopmental Disorders}

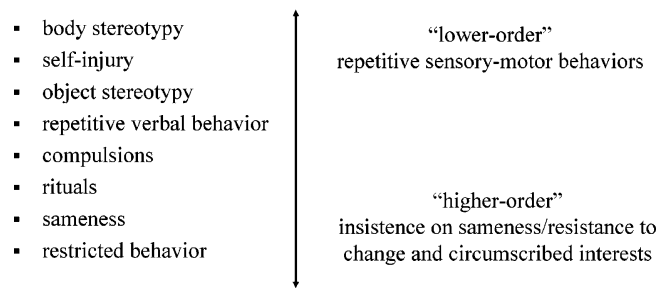

Fig. 1 Specific categories of restricted repetitive behavior ranging from "lower order" or motor behavioral to "higher order" or cognitive behavioral based on Turner [2] via a number of disparate perturbations (e.g., early social deprivation, gene $\mathrm{x}$ environment interactions, etc.).

RRB and normative development

Any consideration of the pathophysiology of repetitive behavior in autism must take into account the ubiquity of RRB in normative development (e.g., [16, 17]). Throughout early childhood, children engage in a number of repetitive motor (e.g., swaying, rocking, flapping) and compulsive and ritualistic behaviors (e.g., insistence on certain clothing or foods, bedtime rituals) [18]. Thelen [19] showed, for example, that infants engaged in a wide variety of repetitive, rhythmical behavior that peaked in frequency at 24 months of age and consumed approximately $40 \%$ of their time. During the preschool years, children begin to exhibit more complex repetitive behaviors that are characterized by a surprising rigidity or inflexibility. They may show an insistence on sameness, rigidity in terms of likes and dislikes, ritualization of daily activities, and even compulsive ordering and arranging until some subjective criterion of "just right" is met [17]. Attachment to a favorite object and perseverating on certain thoughts and topics are also common in preschoolers. Typically developing children also exhibit intense, restricted interests. These intense interests can appear as early as 2 years of age or younger, be relatively long lasting, be exhibited in multiple contexts, and come to the attention of non-family members [20].

As Symons et al. [21] have pointed out, very little is known about the developmental course of repetitive behaviors in children at risk for autism. The continuities and discontinuities in the normative and pathological expression of these behaviors have not been the subject of systematic study. The developmental timing of the transition from normative to pathological repetitive behavior has not been examined, nor have the biological and environmental mechanisms that mediate this transition and the persistence of repetitive behavior. Developmentally normative repetitive behavior calls for a dimensional rather than a categorical, or "disease state," approach. Consistent with this would be an emphasis on mechanisms of experience-dependent neuroplasticity, reviewed in a later section, that drive the shift from normative to pathological.

\section{Specificity of RRB in autism}

An important question to consider is whether individuals with ASD have a unique pattern of RRB and whether this implies differential pathophysiology. It also raises the question of whether different neurobiological mechanisms mediate repetitive sensory motor behavior versus resistance to change versus circumscribed interests. 
We do know that children with ASD between the age of 18 months and 24 months exhibit more frequent repetitive sensory motor behavior and for a longer duration than both intellectually disabled and typically developing controls [22]. This finding, when added to similar observations of older subjects and matched controls [23-27], does not suggest, however, a qualitatively different set of behaviors. Bodfish et al. [8] assessed the occurrence of specific topographies of repetitive behaviors as well as their severity in individuals with intellectual disability with and without autism. The occurrence of each behavior category, except dyskinesias, was higher in the autism group. In addition, autistic subjects exhibited a significantly greater number of topographies of stereotypy and compulsions and significantly greater severity ratings for compulsions, stereotypy, and selfinjury. Again, these differences are largely quantitative, not qualitative. Examination of compulsive behavior in autism suggests little difference in expression from individuals with obsessive compulsive disorder (OCD). McDougle and colleagues reported that individuals with OCD have more cleaning, checking, and counting behavior, and individuals with autism have more hoarding, ordering, touching/tapping/ rubbing, and self-injurious behaviors [28]. When controlling for intellectual level, however, adults with high functioning autism exhibited similar frequencies of OC symptoms to adults with a primary diagnosis of OCD, with only somatic obsessions and repeating rituals being more common in the OCD group [29].

Routines and rituals do seem to occur at a much higher rate in children with autism than age and ability matched control subjects [26, 30, 31]. Moreover, Szatmari et al. [27] reported insistence on sameness and circumscribed interests to be significantly more common in high-functioning individuals with autism than in socially odd psychiatric control subjects. Thus, an elevated pattern of occurrence and severity of RRB, particularly rituals and restricted interests, appears to distinguish autism from other disorders [7, 8, 30]. Repetitive behavior is not specific to autism, however, and no single type (or factor) of RRB is pathognomonic to autism.

Cognitive, sensory, and motor abnormalities and RRB

A related question is whether there are specific cognitive, sensory, or motor abnormalities that co-occur with RRB and provide clues to its pathophysiology. In the cognitive domain, the genesis and maintenance of repetitive behavior has been conceptualized as consequent to deficits in executive function [32]. Executive function is a broad category of cognitive processes involved in the planning and execution of flexible, goal-directed behavior [33]. Aspects of impairment in executive function have been widely demonstrated in individuals with autism, irrespec- tive of intellectual capability. Much of the work suggests impairment in cognitive flexibility [33-35] as well as set shifting and inhibition of pre-potent responses. These deficits would seem to be consistent with "higher order" repetitive behaviors, and indeed, repetitive behavior symptoms have been related to performance deficits in executive functioning tasks [32, 36]. Evans et al. [37] have shown that some executive function tasks, such as set-shifting and response inhibition/motor suppression, are related to the frequency and intensity of compulsive behaviors in typically developing children. In the Lopez et al. study [36], the degree of restricted, repetitive behavior in individuals with autism was correlated positively with deficits on tasks that index cognitive flexibility. Importantly, this association was observed after controlling for level of cognitive function. It should be noted, however, that other groups have either provided only partial support [38] or failed to find a significant association between repetitive behaviors and aspects of executive functioning [39]. In a recent review, Geurts et al. [40] have concluded that there is no consistent evidence for cognitive flexibility deficits in autism and that the link between cognitive flexibility and restricted, repetitive behavior has not been clearly established [40].

Weak central coherence or the preferential processing of specific or local features of the environment rather than global features has also been invoked to account for RRB in autism. Specifically, individuals who exhibit weak central coherence would be expected to have high levels of restricted, repetitive behavior. In typically developing young children, Evans et al. [41] observed that higher levels of repetitive behavior were associated with better performance on the Embedded Figures Task. In children with ASD, however, either a weak association [42] or no association was noted between repetitive behavior and central coherence [43].

In general, sensory processing abnormalities are frequently reported in autism and have been linked to restricted, repetitive behavior [2, 44-46]. Indeed, preoccupation with sensory features (e.g., texture) of stimuli is included as a repetitive behavior in the ICD-10. Repetitive behaviors have been theorized to provide a mechanism to modulate sensory problems resulting in reduced or increased levels of stimulation. Nonetheless, as Rogers and Ozonoff [47] have concluded in a recent review, sensory symptoms do not differentiate autism from other developmental disorders. Moreover, abnormal sensory responses and repetitive behaviors are clearly differentiable. Although there is little evidence functionally linking sensory abnormalities to repetitive behavior, Chen et al. [42] found that, in children with autism, more severe sensory processing abnormalities were associated with more restricted, repetitive behavior.

Motor impairments in children with ASD, including clumsiness, motor incoordination, postural instability, and 
poor performance on standardized tests of motor functioning, have been reported [48-54]. There are also reports of children with ASD with delayed or abnormal attainment of developmental milestones, such as skipping the crawling stage, asymmetry in arms and/or legs when crawling, or uncoordinated arm and leg swings when walking $[55,56]$. It is certainly reasonable to hypothesize that an association exists between motor impairments and, particularly, repetitive sensory motor behaviors. Nonetheless, such a relationship has not been systematically established in autism. Bodfish et al. [57] assessed postural stability in individuals with intellectual and developmental disabilities, with and without stereotyped behavior using a force platform and computerized posturographic techniques. The results showed that the stereotypy group demonstrated markedly different postural movement profiles versus controls and demonstrate that motor control deficits are associated with stereotypy.

In summary, there is little evidence for robust associations between repetitive behavior and specific cognitive, sensory or motor impairments. Thus, abnormalities in these domains identified in individuals with autism would not appear to provide much useful information relevant to the pathophysiology of restricted repetitive behavior.

\section{Genetics of restricted repetitive behavior}

Autism spectrum disorder (ASD) has a strong genetic component with complex inheritance. Concordance rates in monozygotic twins have been reported to range from 60 $91 \%$ as compared to the $0-10 \%$ range reported for dizygotic twins $[58,59]$. The sibling recurrence rate has been estimated to be $4.5 \%$ [60] and estimates of the number of genes involved in ASD range from 3-10 [61, 62] to more than 15 [63]. Several candidate loci for autism have been reported, although there has been little replication across studies. Phenotypic heterogeneity has no doubt confounded the identification of autism susceptibility genes. Therefore, there has been an effort to facilitate genetic research by stratifying sample into more homogeneous groups using "sub-phenotypes," such as age of first words or phrases spoken $[7,64,65]$. RRB may also be used to identify homogenous subgroups within autism [7].

Several lines of evidence indicate that circumscribed interests, rituals, and compulsions have an underlying genetic component. In autism, the repetitive behavior phenotype shows a strong tendency to run within families, indicating a common genetic etiology. Moreover, restricted, repetitive behavior is likely influenced by genes that are largely independent of those that influence the social or communication deficits that make up the remaining diagnostic domains of autism [66-68]. Similar indications come from assessment of behavioral subtypes within OCD, where high levels of particular behaviors, such as symmetry/ ordering or obsessions/checking, confer greater genetic risk among relatives [69].

Use of the restricted, repetitive behavior phenotype has been shown to reduce heterogeneity and has led to the identification of potential ASD susceptibility genes. For example, Shao et al. [70] have found increased linkage evidence at the GABRB3 locus in 15q11-q13 region in families sharing the insistence on sameness factor score. Recently, Brune et al. [71] reported an association between 5HTTLPR long/long genotype of the serotonin transporter gene (SLC6A4) and repetitive sensory-motor behaviors.

Autism family studies have also suggested the familiality of RRB. Silverman et al. [68] examined 212 siblingships with at least one autistic proband and another sibling with either autism or an ASD ("broadly defined multiplex siblingships") ascertained by the ADI-R for sibling concordance pattern of RRBs. Among these, 136 siblingships were defined as "autism multiplex siblingships," while the rest were "broadly defined multiplex siblingships." In this study, evidence for familiality was defined as significantly reduced variability by analysis of variance and covariance in autistic-related domains within siblingships. The familiality of RRB was examined using the ADI-R subdomain and individual scores. Statistically significant familiality was found for D1 (encompassing preoccupation/circumscribed pattern of interest) and D2 (apparently compulsive adherence to nonfunctional routines/rituals) subdomain scores on the ADI-R, especially for encompassing preoccupation/circumscribed patterns of interest and apparently compulsive adherence to nonfunctional routines/rituals. All of the ADI-R items contributing to these categories were also significant. The autism multiplex siblingships had RRB scores suggestive of higher familiality than the whole group ("broadly defined multiplex siblinghips") probably due to reduced heterogeneity. Interestingly, stereotyped and repetitive motor mannerisms (D3 subdomain) and preoccupation with parts of objects or nonfunctional elements of materials (D4 subdomain) did not appear to have significant familiality in studied siblingships. Similar to this study, Szatmari et al. [5] also found evidence for moderate familial aggregation among affected sibling pairs within the Insistence on Sameness (IS) factor in 339 individuals with ASD.

\section{5q11-q13 and RRB}

The chromosome 15q11-q13 region has been implicated in autism and RRB, based on the following observations: 1) maternal duplication of this region is the most common chromosomal abnormality associated with autism [72-81]; 2) genetic markers near GABRB3 within the 15q11-q13 region have been implicated in autism through both linkage and association studies [70, 82-90]; and 3) clinical and 
genetic overlaps between Prader-Willi syndrome (PWS) and ASD. PWS is a rare genetic disorder caused by the structural or functional absence of paternally inherited genes in the $15 \mathrm{q} 11-\mathrm{q} 13$ region. The majority of PWS individuals suffer from high levels of RRB, [91-94] and an increased rate of ASD has been reported among individuals with PWS [95].

As indicated, chromosome 15q11-q13 harbors a set of three GABA receptor subunit genes (GABRB3, GABRA5, and $G A B R G 3)$. For example, Shao et al. [70] developed a novel statistical method, ordered-subset analysis (OSA), to identify a homogeneous subset of families that contribute to overall linkage at a given chromosomal location, and thus to potentially help in the fine mapping and localization of the susceptibility gene within a chromosomal area. In their analysis, increased linkage at the GABRB3 locus in 15q11q13 region was observed in families sharing a high insistence on sameness factor score. Furthermore, four other GABA system genes (GABRA4, GABRB1, GABRR2, and $A B A T)$ have been also associated with autism [96-98].

\section{Dopamine genes and RRB}

Pharmacological studies have established the importance of the nigrostriatal dopamine pathyway in the mediation of stereotypies [1]. Administration of indirect and direct acting dopamine agonists or repeated administration of a potent and selective dopamine uptake inhibitor has been shown to induce stereotypic behaviors or self-mutilation [99, 100]. The severe repetitive self-injurious behaviors in patients with Lesch-Nyhan syndrome have been associated with markedly fewer dopaminergic nerve terminals and cell bodies [101]. Other dopamine related genes implicated in RRB include catechol-o-methyltransferase (COMT) and dopamine transporter (DAT) genes. COMT is a strong candidate gene for schizophrenia, another RRB associated disorder, due to its role in dopamine metabolism and the location of the gene within the deleted region in Velocardiofacial syndrome, a disorder associated with high rates of schizophrenia. DAT knockout mice, so called "hyperdopaminergic mutant mice" showed greater invariance in complex fixed action patterns suggesting an association between abnormal dopamine levels and repetitive behaviors [102]. However, few molecular genetic studies have examined the association between dopamine system related genes and autism and there is no evidence to date for dopamine genes playing a role in RRB in autism.

\section{Glutamate genes and RRB}

The excitatory neurotransmitter glutamate has been implicated in RRB, based on its role in cortico-striatal-thalamic-cortical circuitry. Moreover, spontaneous repetitive behavior in mice appears to be mediated, at least in part, through the corticostriatal glutamatergic system [103, 104]. Furthermore, SLC1A1, a glutamate transporter gene, has been identified as a susceptibility gene for obsessive compulsive disorder (OCD) $[105,106]$ and was one of several genes centered under the highest linkage peak in the recently completed Autism Genome Project scan [80]. In addition, several lines of evidence implicate glutamate system genes as autism risk genes [107] including evidence for a positive association between two glutamate receptor subunit genes (GRIK2 and GRIN2A) and autism [98, 108, 109].

Other candidate genes related to excitatory synapses include two neuroligin genes ( $N L G N 3$ and $N L G N 4 X$ ), neurexin 1, neurexin 3 and SHANK3. Neuroligins function as ligands for the neurexin family of cell surface receptors. Interestingly, two putative missense variants and hemizygous deletion of coding exons of neurexin 1 (NRXN1) have been also reported in ASD [80, 110]. Furthermore, a strong linkage signal to compulsive hoarding was detected near neurexin 3 (NRXN3) among multiplex OCD families with two or more hoarding relatives [111]. SHANK3 is related to Prosap1 in rat, a scaffold protein highly enriched in the postsynaptic density of excitatory synapses [112]. SHANK3 is one of the genes disrupted in patients with the $22 \mathrm{q} 13.3$ deletion syndrome but has yet to be implicated in RRB [113]. In mice, overexpression and deletion of genes that code for other glutamate synapse proteins were shown to result in repetitive behavior (see "Animal models of restricted repetitive behavior").

\section{Serotonin genes and RRB}

The serotonin transporter (5-HTT) has been considered a strong candidate gene for autism based on reports of hyperserotonemia and the efficacy of selective 5-HT reuptake inhibitors (SSRIs) in treating repetitive behaviors. Although association studies involving the functional insertion/deletion polymorphism in the promoter (5HTTLPR) and a polymorphism in intron 2 have been inconclusive (possibly due to phenotypic heterogeneity), several groups identified evidence for genetic linkage of autism to the chromosome $17 \mathrm{q} 11.2$ region that harbors the 5-HTT locus (SLC6A4) [88, 114-116]. In a family based association study, Sutcliffe et al. (2005) found an association between novel variants at the serotonin transporter locus (SLC6A4) and rigid compulsive behavior. Additionally, Brune et al. [71] also found an association between 5HTTLPR long/long genotype of the serotonin transporter gene (SLC6A4) and repetitive sensory-motor behaviors.

Associations of the 5-HT transporter and RRB are consistent with the dense innervation of cortical-basal ganglia circuitry by 5-HT and the expression of many of the 5-HT receptor sub-types in basal ganglia [117]. In 
addition, serotonin provides most of the innervation of the pre-frontal cortex including the motor cortex and 5-HT projections from raphe nuclei innervate both dopaminergic and GABAergic cells in substantia nigra and their terminal fields. Functionally, tryptophan depletion was shown to worsen repetitive motor behaviors in adults with autism [118] and 5-HT $\mathrm{H}_{1 \mathrm{D}}$ agonist-induced growth hormone response was positively correlated with baseline compulsion scores in subjects with autism [119].

\section{Genetic syndromes associated with RRB}

Specific, relatively rare, genetic syndromes are also associated with RRB [120]. PWS (OMIM 176270), caused by an absence of paternal contribution in the 15q11-q13 region, with an estimated incidence rate of $\sim 1$ in 15,000 [121], has shown to be associated with substantial RRB [9194]. Skin-picking is reported in $69-100 \%$ of individuals with PWS [91, 122-126]. Prominent obsessive compulsive symptoms (hoarding, ordering/arranging, concerns with symmetry/ exactness, rewriting, need to tell/know/ask) were also reported in 37-58\% of individuals with PWS [127]. A recent study also confirmed that individuals with PWS have higher hoarding behavior and preference for routines when compared with other genetic syndromes associated with RRB; however, this study revealed lower stereotypic and tidying up behaviors [120]. Absence of maternally inherited genes in the same chromosomal locus produces Angelman syndrome (OMIM 105830, AS). Although more severely affected than PWS patients [128, 129], individuals with AS exhibit a less severe repetitive behavior phenotype which includes stereotypic hand flapping and fascination with water [130].

Fragile X syndrome (OMIM 300624, FXS) is the most common inherited cause of intellectual disability and autism. FXS is caused by an expansion of a single trinucleotide gene sequence (CGG) in the FMR-1 gene, and results in a failure to express the FMR-1 protein that is required for normal neural development. Individuals with FXS show a high frequency of occurrence of hand flapping, tidying up, lining up, restricted conversation, echolalia, preference for routines, just right behavior, repetitive phrases and restricted interests [120, 131, 132].

Rett syndrome (OMIM 312750, RS), a pervasive developmental disorder, is caused by mutations in the gene MECP2 located on the X chromosome (Xq28) and occurs almost exclusively in females. The affected infants show normal prenatal and postnatal development for the first 5 months, which is followed by a deceleration of head growth rate, loss of acquired skills, impairments in social communication, and characteristic stereotypic repetitive hand movements such as mouthing or wringing [133].

Cri-du-Chat syndrome (OMIM 123450) caused by a missing part of chromosome 5 (5p15) [134] is associated with moderate to severe mental retardation as well as stereotypic body rocking, echolalia, and attachments to objects $[120,135,136]$. Cornelia de Lange syndrome (OMIM 122470, 300592, 610759) is caused by mutations in genes encoding components of cohesion complex, such as the NIPBL gene in the $5 \mathrm{p} 13$, the SMC1L1 gene in the $\mathrm{Xp11.2}$, and the SMC3 gene in the 10q25. Cornelia de Lange syndrome is also associated with mild to profound mental retardation, stereotypic movements (e.g., body rocking, body postures), spinning objects, lining up, tidying up, and ritualistic behavior $[120,137,138]$.

Lowe syndrome (OMIM 309000; Oculocerebrorenal syndrome) is an X-linked recessive disorder associated with the gene $O C R L$, and characterized by hydrophthalmia, cataracts, intellectual disabilities, aminoaciduria, reduced renal ammonia production and vitamin D-resistant rickets. The majority of Individuals with Lowe syndrome show repetitive hand movements, and lining up behaviors [120, 139].

Smith-Magenis syndrome (OMIM 182290) is caused in most cases $(90 \%)$ by a $3.7-\mathrm{Mb}$ interstitial deletion in chromosome 17p11.2. The disorder can also be caused by mutations in the RAII gene, which is within the SmithMagenis chromosome region. The individuals with SmithMagenis syndrome show stereotypic body movements (e.g., mouthing objects, hand teeth grinding, body rocking, spinning/twirling, lick and flip), restricted interests, obsession, repetitive speech, ritualistic behavior, and attachment to people (preference for adults) [120, 140-142].

\section{Summary}

It is clear that autism has a strong genetic etiology and that genes controlling RRB are likely independent of genes controlling social and communication deficits. Clinical and animal studies have provided only very limited findings with respect to specific genes or genetic loci that may control restricted, repetitive behavior, however. Moreover, repetitive behavior has been linked to mutations at disparate chromosomal loci. This is not surprising given the complexity and heterogeneity of these behaviors. One implication of the genetic findings is that pathological repetitive behavior is mediated by complex circuitry involving a very large number of genes. Mutations of even one or a few such genes could result in significant disruptions to this circuitry and full expression of the behavioral phenotype (e.g., [104]).

\section{Neuropathology of restricted, repetitive behavior in autism}

There have been no attempts of which we are aware to link post-mortem neuropathological findings to restricted repeti- 
tive behavior in individuals with autism. Indeed, as pointed out by Amaral et al. [143], there is also no evidence from post-mortem studies for basal ganglia or thalamus abnormalities, brain regions often linked to repetitive behavior (see following sections).

There are some neuroimaging findings, however, that link repetitive behavior to regional volumetric differences. For example, Sears et al. [144] reported a significant negative association between caudate volume and three ADI repetitive behavior items: difficulties with minor changes in routine, compulsions/rituals, and complex mannerisms. Hollander et al. [145] found increased right caudate volumes in individuals with autism and reported a positive correlation between right caudate volumes and ADI repetitive behavior domain total scores. This relationship was driven by the association between right caudate volume and the insistence on sameness/resistance to change factor scores. The same pattern was observed when putamen volumes were correlated with repetitive behavior scores. Rojas et al. [146] in a study of regional grey matter volume, found increased right caudate gray matter volume in subjects with ASD after controlling for age and whole brain grey matter volume. In addition, they reported significant positive partial correlations with the ADI-R repetitive and stereotyped behavior domain in the caudate. Similar correlations were also found in the left inferior frontal gyrus and right amygdala. Smaller volumes of the superior temporal gyri, left post-central gyrus and cerebellar regions were associated with worse repetitive behavior domain scores. In a study of exploratory behavior of young children with autism, Pierce and Courchesne [147] found a positive correlation between repetitive behavior exhibited in the experimental setting of an exploration task and frontal lobe volume. This measure of repetitive behavior was negatively correlated with cerebellar vermis volume. These neuroanatomic measures were not associated with ADI-R or ADOS repetitive behavior scores, however.

Restricted repetitive behavior has also been linked to activation of the anterior cingulate cortex (ACC) in a fMRI study of response monitoring [148]. An anti-saccade task, which involves suppression of the pre-potent response of looking toward rather than away from a stimulus, was used. A high functioning ASD group showed significantly higher error rates in the anti-saccade condition and significantly increased ACC activation for correct trials. Moreover, higher ADI-R repetitive behavior scores were associated with greater ACC activation during correct trials with repetitive sensorimotor behavior scores more strongly related to ACC activation than resistance to change/ insistence on sameness factor scores. This link between overactive response monitoring and RRB in ASD complements the finding of an exaggerated ACC response to correct trials observed with OCD subjects.
Shafritz et al. [149] examined the neural correlates of both a response shifting and a set shifting cognitive task in individuals with high-functioning autism using fMRI. Compared to controls, individuals with autism showed deficits in response shifting but, surprisingly, not cognitive set shifting. These subjects also showed reduced activation in frontal, striatal, and parietal regions during these trials. The severity of restricted, repetitive behaviors was negatively correlated with activation in anterior cingulate and posterior parietal regions. These data support a relationship between deficits in executive function, restricted repetitive behavior, and fronto-striatal circuitry.

\section{Animal models of restricted repetitive behavior}

Animal models relevant to restricted, repetitive behavior in humans generally fall into three classes: repetitive behavior associated with 1) targeted insults to the CNS; 2) administration of specific pharmacological agents; and 3) exposure to restricted environments and experience [150].

\section{Repetitive behavior and targeted CNS insult}

A repetitive behavior phenotype has been observed in several mutant mouse models. For example, mice expressing truncated $\mathrm{MeCP} 2$ protein exhibit repetitive forelimb movements resembling the distinctive hand stereotypies (e.g., hand-wringing, waving, and clapping) observed in Rett syndrome patients [151, 152]. The gabrb3 homozygous knockout mouse also shows stereotyped behavior such as intense circling or "tail-chasing" which may continue for hours $[153,154]$. As described in a previous section, this gene, which codes for the beta3 subunit of the $\mathrm{GABA}_{\mathrm{A}}$ receptor, lies within the q11-13 region of chromosome 15 . Deletions of this region are associated with Prader-Willi syndrome, of which compulsive behaviors are a particularly salient feature of the behavioral phenotype [155]. Compulsive grooming leading to hair removal and selfinflicted wounds has been identified as a major behavioral phenotype of the Hoxb8 homozygous mutant mouse [156] and the Sapap3 KO mouse [104]. In the latter model, the SAPAP3 protein is expressed selectively in glutamate synapses in striatum, whereas high levels of expression of Hoxb8 were observed in brain regions known to comprise circuitry mediating OCD symptoms in patients. These models are particularly relevant to trichotillomania (compulsive hair pulling) and self-injurious behavior. Interestingly, an amyloid precursor protein (APP) transgenic mouse model of Alzheimer's disease (TgCRND8) has been reported to exhibit marked stereotypies (e.g., jumping, cage top circling) with the former topography being exhibited exclusively by transgenic animals [157]. This finding is consistent with the 
repetitive behavior reported in fronto-temporal dementia and Alzheimer's disease. Of interest given the relationship between Alzheimer's disease and Down syndrome, is the observation that $T s 65 D n$ mice, a model for Down syndrome, exhibit repetitive jumping and cage-top twirling [158]. Transgenic animals overexpressing neuroligin2 (TgNL2) were shown to have altered synapse development and neuronal excitability. Behaviorally, these animals exhibited limb clasping similar to $M E C P 2 \mathrm{KO}$ mice and Rett syndrome patients. Moreover, TNL2 but not WT mice exhibited stereotyped vertical jumping in both an open field and the home cage [159].

Other animal models have pointed to the role of nongenomic factors in RRB. For example, exposure to valproic acid on embryonic day 12.5 in rats results in increased time spent engaged in stereotypic activity [160-162]. The stereotypies expressed by the valproate treated rats were attenuated by housing in an enriched environment [163]. Repetitive behavior has also been linked to viral infection and lesion-induced damage during early development. For example, intracerebral inoculation of newborn rats with Borna disease virus results in spontaneous stereotypies [164] and, in non-human primates, early damage to amygdala, hippocampal formation and adjacent temporal cortex resulted in a number of behavioral abnormalities including stereotypies [165]. A delayed (after year 1 of life) emergence of repetitive motor behavior following amygdala or hippocampal lesions in macaque infants has been reported by Bauman et al. [166]. This developmental effect is consistent with rodent work showing a delayed effect of similar lesions on frontal lobes and sub-cortical dopamine function [167]. Interestingly, in the Bauman study, a distinct pattern of repetitive behavior was associated with each type of lesion with amygdala damage inducing self-directed behaviors and hippocampal lesions inducing repetitive head twisting. A very provocative non-human primate study from this same research group [168] provides evidence for a potential autoimmune etiology of repetitive behavior in at least some individuals. Pregnant rhesus monkeys were exposed to IgG purified from serum collected from mothers who had at least two children with ASD. Offspring of monkeys treated in this way exhibited spontaneous whole body stereotypies that persisted in the 6 months following weaning and that were observed in multiple test conditions. Prenatal exposure to IgG purified from mothers of typically developing children had no such effect. Exposure to maternally derived IgGs that cross the placenta has been implicated in other disorders involving tics and compulsive disorder.

It is important to point out that for many of these studies, repetitive behavior was not the focus or rationale for the work. Thus, the repetitive behavior observed following the CNS insult has generally not been well characterized.
The Amaral lab studies $[166,168]$ provide an important exception to this generalization. Further, little systematic effort has gone into investigating the pathophysiology associated with the expression of repetitive behavior in many of the models cited.

Restricted, repetitive behavior in inbred mouse strains

In the course of behavioral testing a variety of inbred mouse strains for autistic-like traits, Moy et al. [169, 170] observed serendipitously that C58/J mice displayed nondrug related stereotyped jumping and backward flipping behaviors. In addition, compared to control strains, these mice exhibit reduced exploratory behavior. A similar behavioral phenotype has been reported in the C57BL/10 strain [171] with mice of this strain exhibiting spontaneous repetitive vertical jumping with no such behavior observed in the closely related C57BL/6 strain. We have confirmed both sets of observations (unpublished findings). These two inbred mouse strains provide an opportunity to model aspects of the abnormal repetitive behavior symptom domain of autism in a model amenable to genetic dissection.

\section{Drug-induced repetitive behavior}

By far, most of what has been learned about the neurobiological basis of repetitive motor behavior comes from studies of drug induced stereotyped behavior in animals. Early experiments established the importance of the basal ganglia in the mediation of repetitive behaviors by showing that dopamine or a dopamine agonist (e.g., apomorphine) injected into the striatum induced stereotyped behavior in rats (e.g. [172]). Similarly, intrastriatal administration of the glutamate receptor ligand, NMDA, also induced stereotyped behavior [173]. Intracortical manipulations enhancing the activity of excitatory corticostriatal projections exacerbate the expression of stereotypy. For instance, administration of either the $\mathrm{D}_{2}$ antagonist sulpiride or the GABA antagonist bicuculline into the frontal cortex enhances the motor stimulatory effects of amphetamine [174, 175]. Conversely, amphetamineinduced stereotypy can be attenuated via intracortical infusion of DA or GABAergic agonists [175]. Experiments in which the expression of drug-induced stereotypy was shown to be sensitive to manipulations in the substantia nigra pars reticulata (SNpr) and the subthalamic nucleus (STN) also support the hypothesized role of cortical-basal ganglia circuitry in repetitive behaviors $[176,177]$. These, and many other relevant findings, provide clear evidence of the pre-eminent role played by cortical-basal ganglia circuitry in the expression of repetitive motor behaviors. 
Repetitive behavior and environmental restriction

Abnormal repetitive behaviors are commonly displayed in animals housed in restricted (e.g., zoo, farm, laboratory) environments, as well as animals subjected to early social deprivation [178]. Indeed, repetitive behaviors are the most common category of abnormal behavior observed in confined animals [179]. Some examples of aberrant repetitive behaviors observed in animals maintained in confinement include crib-biting and head-shaking in horses [180-182] and head-twirling in mink [183]. Our work has employed deer mice (Peromyscus maniculatus) which exhibit repetitive hindlimb jumping and backward somersaulting as a consequence of being reared in standard laboratory caging. These behaviors occur at a high rate, persist across much of the life of the animal and appear relatively early in development, sometimes as early as weaning.

Although experientially-induced stereotypies share some similarities with drug-induced stereotypies, they can be dissociated. For example, in our own studies, neither systemic nor intrastriatal administration of the dopamine agonist apomorphine increased cage related stereotypies in deer mice, although other repetitive behaviors (e.g., stereotyped sniffing) were observed [184, 185]. These results were consistent with work done showing that neither apomorphine nor the NDMA antagonist MK-801 affected environmentally induced stereotypies in bank voles [186, 187].

Finally, animal models focused on repetitive behavior induced by experiential restriction may not, at first glance, seem relevant to autism. We would argue, however, that the early occurrence of social, communicative and adaptive behavior deficits in young children with autism likely markedly attenuate experience-dependent behavioral and brain development. Moreover, there is evidence that environmental restriction (e.g., orphanages) can induce repetitive behavior in children.

\section{Resistance to change/insistence on sameness}

Most animal models of repetitive behavior have generally focused on stereotyped motor behaviors which, in animals, are easier to model than, for example, rituals or insistence on sameness. Nevertheless, some animal work has addressed the domain of cognitive rigidity or resistance to change characteristic of RRB. Cognitive flexibility, or resistance to change, can be assessed in animals using a variety of tasks that range in complexity from response extinction to reversal learning to intra- and extradimensional set shifting (e.g., [188]). Recent work conducted with several different species has demonstrated that motor stereotypies are inversely correlated with measures of cognitive flexibility. For example, in bank voles and bears extinction learning was significantly inversely correlated with the amount of environmental restriction-induced stereotypy exhibited [189, 190]. Similarly, Orange wing Amazon parrots were assessed for stereotypy and performance on a variation of a gambling task which indexed the tendency to repeat responses or perseverate. Animals with higher stereotypy scores exhibited greater sequential dependency in their responses on this task [191]. In our own work, we have examined the performance of deer mice in a procedural learning task that involved learning to turn down the right or left arm of a T-maze for reinforcement. Following acquisition, the reinforced arm was reversed. Our results indicate that high levels of stereotypy in deer mice were associated with deficits in reversal learning in the T-maze [192]. In this study, we showed that environmental enrichment was associated with better reversal learning as well as attenuating stereotyped motor behavior. The relationship between cognitive rigidity (deficits in set shifting, extinction, and reversal learning) and motor stereotypy is perhaps not surprising given the common mediation by cortical-basal ganglia pathways. Much greater emphasis needs to be placed on modeling "higher order" repetitive behaviors in animals in future studies, however.

\section{Neurocircuitry of repetitive behavior}

Basal ganglia pathways

The circuitry hypothesized to mediate the expression of repetitive behavior includes pathways that link select areas of cortex and basal ganglia (Fig. 2). The striatum, a key

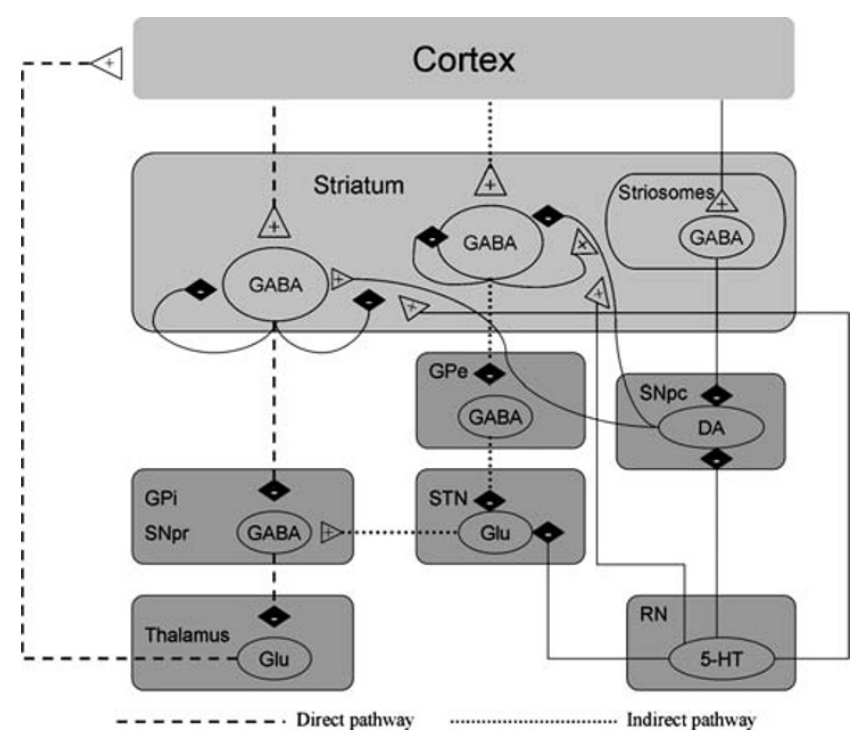

Fig. 2 Schematic of cortical basal ganglia circuitry illustrating direct and indirect basal ganglia pathways as well as the striosomal pathway 
component of this circuitry, has a compartmental organization with patchy areas or striosomes distributed throughout an extra-striosomal matrix. Striosomal projection neurons receive input preferentially from limbic cortical areas (e.g., orbitofrontal cortex, anterior cingulate/posterior medial PFC) and, in turn, project to substantia nigra pars compacta [193, 194]. Thus, striosomal projections can directly mediate nigrostriatal dopamine pathway activity and, in turn, influence reinforced behavior. Support for this hypothesis is supported by the work of White and Hiroi [195] who showed that high rates of intracranial selfstimulation (ICSS) were associated with electrode placement either in or next to striosomes. In contrast to reinforced behavior, there is some evidence in rats that the extrastriosomal matrix mediates "normal" sensory-motor function (e.g., grooming, locomotion)[196]. Recent evidence from non-human primates has suggested that striosomal output, at least in these animals, innervates SNpr and GP as well as SNpc [197]. Thus, these pathways also may not be as segregated as once believed.

The matrix compartment of the striatum contains a majority of the medium spiny GABA projection neurons as well as many of its interneurons. These neurons receive projections from sensory-motor and associative areas of cortex, and, in turn, give rise to the direct and indirect pathways. In the direct pathway, $\mathrm{D}_{1}$ dopamine receptors are co-expressed with glutamate receptors on GABAergic medium spiny neurons of the striatum neurons [198-200]. These neurons also express the neuropeptides dynorphin and substance $\mathrm{P}$ as well as $\mathrm{A}_{1}$ adenosine receptors. These neurons send projections from the striatum to the internal segment of the globus pallidus (GPi) and substantia nigra pars reticulata ( $\mathrm{SNpr}$ ). In the indirect pathway, $\mathrm{D}_{2}$ receptors are co-expressed with the glutamate receptors on striatal medium spiny neurons neurons [198-200]. These neurons also express the neuropeptide enkephalin and $\mathrm{A}_{2 \mathrm{~A}}$ adenosine receptors. These neurons project to the external segment of globus pallidus (GPe) and then to subthalamic nucleus before projecting to GPi and SNpr. Output from the $\mathrm{GPi} / \mathrm{SNpr}$ goes to thalamus and then on to cortex to complete the circuitry.

In primates, striatal efferents appear to be highly collateralized and do not innervate $\mathrm{GPe}, \mathrm{GPi}$, or SN exclusively [197]. In rats, the large majority of striatal neurons were shown to project to more than one striatal site [201]. In addition, a significant number of neurons express both $\mathrm{D}_{1}$ and $\mathrm{D}_{2}$ dopamine receptors as well as enkephalin and Substance $\mathrm{P}$, although direct pathway projection neurons contain high levels of $\mathrm{D}_{1}$ receptors and low levels of $\mathrm{D}_{2}$ receptors, with the converse being true for the indirect pathway [202]. Thus, the two pathways are not as segregated as once thought. Nonetheless, this model of basal ganglia function remains a useful framework for examining mechanisms of disordered motor, cognitive, and affective behavior.

Repetitive behavior and cortical-basal ganglia circuitry

The very few studies (reviewed in a previous section) of individuals with autism that have linked MRI findings to restricted repetitive behavior have implicated nuclei (e.g., caudate) that make up cortico-striato-thalamo-cortical circuitry. Additional evidence for altered cortical-basal ganglia circuitry comes from Turner et al. [203] who assessed functional connectivity between caudate and cortical areas in autism spectrum subjects by fMRI during a simple visuomotor coordination task. Compared to matched controls, subjects with autism exhibited atypical connectivity patterns between caudate and cortical areas. Atypical fronto-striatal connectivity was also reported by Horwitz et al. [204] who assessed regional cerebral metabolic rates for glucose using positron emission tomography. The autistic group showed significantly lower correlations of the thalamus and caudate with frontal and parietal region. Indeed, many of these correlations were negative in the autism group and positive in controls. It should be noted, however, that these last two studies did not attempt to assess repetitive behavior or relate such behavior to neuroimaging results. Nonetheless, atypical cortical-basal ganglia connectivity would be consistent with the development and expression of RRB.

Perturbations in cortical-basal ganglia circuitry appear to be associated with repetitive behavior in non-autism populations, as well. For example, Kates et al. [205] compared boys with stereotypies who had no other known developmental or neurological disorder with matched controls. In this study, decreases in frontal white matter were found even after total white matter volume was taken into account. Caudate volumes did not differ between groups when expressed relative to total brain volume. MRI findings have revealed alterations in putamen volume of individuals suffering from trichotillomania or repetitive hair-pulling [206]. Similarly, magnetic stimulation and fMRI studies demonstrate increased cortical excitability and abnormal cortico-basal ganglia activation, respectively, in individuals with Tourette syndrome [207]. Caudate volumes in children with Tourette syndrome predicted the severity of tic and obsessive-compulsive symptoms in early adulthood [208], and, in adults with TS, Peterson et al. [209] showed that during tic suppression, prefrontal cortical, thalamic and basal ganglia areas were activated and that these activations were inversely correlated with tic severity. Finally, considerable evidence from functional imaging studies of OCD patients supports a generalization of altered neuronal activity in key cortical (e.g., orbitofrontal cortex, anterior cingulate) and sub-cortical (caudate 
nucleus, thalamus) areas making up cortical basal ganglia circuitry. These studies indicate that symptomatology was significantly correlated with alterations in activation of the orbito-frontal cortex [210] and head of the caudate, particularly. OCD patients have also been reported to have fewer striatal D2 dopamine receptors, suggesting a potential loss of activity of the indirect pathway [211] or reduced number of autoreceptors leading to decreased autoinhibition.

Our studies of early socially deprived non-human primates also support the association of repetitive behavior and alterations in cortical-basal ganglia function. Stereotyped behavior, a predictable consequence of early social deprivation in this species, was associated with dopamine receptor supersensitivity [212], loss of dopamine innervation in striatum and dopamine cells in substantia nigra, and decreases in medium spiny striatal projection neurons as indexed by neuropeptide staining [213].

Further evidence for the importance of cortico-basal ganglia circuitry in repetitive behavior comes from phenotypic studies of the SAPAP3 knock out mouse [104]. $S A P A P 3$ is post-synaptic scaffolding protein, highly expressed in striatum, and important in regulating glutamatergic cortico-striatal synapses. Mice homozygous for the gene deletion express a behavioral phenotype involving excessive grooming to the point of inducing lesions to the head, neck, and snout. In addition, these animals exhibited increased anxiety-like behavior in several standard behavioral paradigms and alterations in AMPA and NMDA receptor dependent transmission at cortico-striatal synapses. Interestingly, administration of the serotonin uptake inhibitor fluoxetine given systemically for 6 days reversed the compulsive grooming as well as the anxiety-like behavior. Finally, the behavioral phenotype was rescued by transduction of the SAPAP3 gene into preweaning mice. This elegant study demonstrates that deletion of even a single protein that functions to maintain the activity of cortical-basal ganglia circuitry can result in a robust repetitive behavior phenotype. Moreover, a SSRI can reverse the effects of loss of a glutamate synapse protein. This suggest that circuitry of this complexity can be effectively modulated in multiple ways and underscores the danger of making inferences about pathophysiology based on treatment. Finally, it provides some evidence for an association of RRB and anxiety.

Grabli et al. [214] have reported that stereotyped behavior (e.g., licking and biting of fingers) was induced in monkeys when the GABA antagonist bicuculline was microinjected into the limbic aspect of the GPe (part of the indirect pathway). In a follow-up study [215], this group showed that deep brain stimulation (DBS) applied to the subthalamic nucleus (STN) dramatically reduced these drug-induced repetitive behaviors without affecting a control motor task. The importance of the STN was also highlighted by Winter et al. [216] who have shown that rats that sustained ibotenic acid lesions to this nucleus exhibited an increase in compulsive lever pressing in the signal attenuation model of OCD. This same research group has also shown that bilateral high frequency stimulation of the STN as well as pharmacological inactivation of the STN reduced compulsive checking in rats induced by the dopamine agonist quinpirole [216]. This latter finding is consistent with clinical observations that DBS applied to the STN reduced the severity of symptoms in previously treatment refractory OCD patients [217].

Our studies with deer mice have shown that early environmental enrichment markedly attenuated the development of stereotypy. Moreover, brain changes associated with this behavioral outcome pointed to selective effects in cortical basal ganglia circuitry (see [218]). In more direct tests of the role of cortical-basal ganglia circuitry in mediating stereotypy in deer mice we blocked corticostriatal glutamatergic projections or nigrostriatal dopaminergic projections with selective pharmacological agents [219]. Stereotypy was attenuated selectively (i.e., nonstereotypic motor behavior was not affected) via intrastriatal administration of either the NMDA receptor antagonist MK-801 or the $\mathrm{D}_{1}$ dopamine receptor antagonist SCH23390. Importantly, no such attenuation was observed following intrastriatal administration of the $\mathrm{D}_{2}$ dopamine receptor antagonist raclopride [185].

Dysregulation of cortico-striato-thalamo-cortical circuitry associated with motor disorders is thought to be due to an imbalance between the direct and indirect pathways comprising this circuit. As dynorphin and enkephalin serve as markers for direct and indirect pathway neurons, respectively, concentrations of these striatal neuropeptides were measured to index the relative activation of these basal ganglia pathways in stereotypic deer mice [220]. Measurements were made in dorsolateral striatum using deer mice exhibiting different levels of spontaneous stereotypy. Results indicated significantly increased dynorphin/enkephalin content ratios in highstereotypy mice relative to low-stereotypy mice. This ratio difference was due to significantly lower leu-enkephalin content in high stereotypy mice. Moreover, a significant positive correlation was found between the dynorphin/ enkephalin content ratio and frequency of stereotypy in these mice whereas a significant negative correlation was found for enkephalin content and stereotypy. These data are consistent with the hypothesis that spontaneous stereotypic behavior is expressed as a consequence of relative hyperactivity along cortico-basal ganglia-cortical feedback circuits involving the direct pathway, but suggest that perturbations to the indirect pathway may give rise to such imbalanced activity.

To extend these findings, we assessed indirect pathway activation relative to stereotypy by measuring neuronal metabolic activation of the STN, a key brain region in the 
indirect pathway [221]. Using cytochrome oxidase (CO) histochemistry to index long-term neuronal activation, we found that $\mathrm{CO}$ staining in the subthalamic nucleus (STN) was significantly reduced in high-stereotypy mice. Further, CO staining was significantly negatively correlated with the frequency of stereotypy. Thus, higher rates of spontaneous stereotypy were associated with reduced neuronal activation of the indirect pathway. Finally, in ongoing work in our lab, we have pilot findings that suggest that pharmacological activation of the indirect pathway reduces repetitive behavior in deer mice in a selective fashion. Conversely, pharmacological blockade of the indirect pathway induces repetitive behavior in deer mice (unpublished observations).

\section{Long term neuroadaptations and RRB}

The development and persistence of repetitive behavior in autism presumably involves long-term, experiencedependent striatal plasticity. Evidence for such dynamic neuroadaptation comes from studies of habit learning or habit formation. As Graybiel [222] has suggested, repetitive behaviors can be seen as "extreme" habits. Like RRB, habits can have cognitive and motor components and represent sequential, repetitive behaviors that when triggered by relevant stimuli proceed to completion without conscious cognitive control or clear contingency. Habit formation, typically examined in the context of procedural learning, involves adaptations of cortical-basal ganglia loops and chronic electrophysiological monitoring of ensembles of neurons in rodents and non-human primates have revealed discrete shifts in patterns of neural activity that overlay the transition from goal directed to habit driven behavior (reviewed in [222]). The relevance of this work to RRB in autism is highlighted by the finding that amphetamine sensitization, another model of dopamine-dependent striatal plasticity, accelerates the development of habit learning or formation [223]. Amphetamine sensitization which involves long-term neuronal changes following repeated, intermittent drug exposure also results in significantly increased levels of repetitive motor behavior [224].

Additional evidence for the role of experience-dependent basal ganglia pathway adaptations in the transition from variable to stereotyped responding comes from work on birdsong. For example, oscine songbirds imitate older members of their species and progress through stages where song production starts out highly variable but becomes increasingly stereotyped. Recent studies have determined that lesions of the anterior forebrain pathway (AFP; homologous to basal ganglia thalamo-cortical loops) in juvenile zebra finches markedly disrupt song development but have few effects in adult birds. Specifically, inactivation of an AFP nucleus (lateral magnocellular nucleus of the nidopallium or LMAN) results in a dramatic loss of variability in song typical of juveniles [225]. Instead song production is highly stereotyped, similar to that observed in adults.

Molecular mechanisms involved in experience-dependent neuroadaptation that give rise to repetitive behavior appear to involve transcription factors which can effect changes in gene expression. Nestler et al. [226, 227] have suggested that the transcription factor $\Delta \mathrm{FosB}$ may be a good candidate for mediating long term striatal plasticity. Following chronic stimulation $\triangle \mathrm{FosB}$ undergoes post-translational modifications and generates highly stable isoforms which heterodimerize with Jun proteins and bind to AP-1 sites expressed in the promoter regions of genes encoding key striatal proteins (e.g., AMPA glutamate receptor subunit, GluR2, and dynorphin; [228-230]). $\Delta$ FosB is induced after chronic exposure to stimuli relevant to repetitive behavior (e.g., stress, drugs of abuse, chronic wheel running) and persists in brain for long periods of time [231]. Thus, $\Delta$ FosB might have a more general role in the development of repetitive behavior induced by a wide range of stimuli.

Chronic L-DOPA treatment in Parkinson's disease (PD) patients is associated with the development of repetitive behavior including compulsions and dyskinesias. In relevant animal models, L-DOPA-induced dyskinesias in rats are correlated with increased ratio of FosB in striosomes, relative to matrix $[232,233]$. In a primate model of $\mathrm{PD}$, striatal $\triangle$ FosB was markedly elevated following pulsatile administration of a $\mathrm{D}_{1}$ dopamine agonist but only in animals which developed dyskinesias [234]. These FosBrelated proteins appear to be expressed preferentially in direct pathway neurons [233]. In addition, activation of ERK, the extracellular-regulated kinases that mediates down-stream transcription, is restricted to the direct pathway neurons in mouse models of L-DOPA-induced dyskinesias [235]. Compulsive wheel running also induces $\Delta \mathrm{FosB}$ in striatal direct pathway neurons. Interestingly, transgenic animals that selectively overexpress $\Delta \mathrm{FosB}$ in these projection neurons exhibit excessive or compulsive wheel running, whereas wheel running is significantly inhibited in animals that overexpress the gene in enkephalin containing or indirect pathway projection neurons [236].

Fos related proteins are also associated with the development of stereotypies following repeated intermittent exposure to drugs such as cocaine and amphetamine (i.e., sensitization). In this model, increased Fos protein expression is preferentially exhibited in striatal striosomes (e.g., [237]). Indeed, this increased striosomal expression of Fos and FosB following drug exposure reliably predicts motor stereotypies [224]. Such plasticity related changes also appear to be progressively more evident in the dorsal aspect of the striatum with increased drug exposure. In addition, the shift in metabolic activity to striosomes appears to be due largely to a decline in matrix activity. This shift from 
matrix to striosomes could reflect a shift toward more motivationally driven behavior with a consequent narrowing of focus and escalation of repetition [238]. As yet, there is no evidence for either a matrix to striosome shift or a ventral to dorsal striatum shift in neuronal activation in non-drug induced repetitive behavior.

\section{Summary}

Restricted, repetitive behaviors are a heterogeneous group of behaviors, ranging from stereotypic body movements to more cognitively mediated symptoms such as restricted (circumscribed) interests or preoccupations [1, 239]. RRB is most strongly associated with autism but occurs in a number of other clinical disorders as well as in typical development. There does not seem to be a pattern or category of RRB that is unique or specific to autism and RRB does not seem to be robustly correlated with specific cognitive, sensory or motor abnormalities or deficits in autism. Despite its clinical significance, little is known about the pathophysiology of RRB. As we have indicated, specific genetic alterations appear to be important risk factors to isolate as there are findings from both clinical and animal models studies linking repetitive behavior to genetic mutations. Moreover, a number of specific genetic syndromes have RRB as part of the clinical phenotype. As the pathophysiological sequelae of these genetic mutations are mapped out, we will have additional clues as to the biological substrate of aberrant repetitive behavior. Gene by environment relationships seems crucial as discrete genetic risk factors may interact with broad experiential factors resulting in the extremes in repetitive behavior phenotypic expression that characterize autism. For example, restricted or impoverished environments have often been associated with repetitive behavior in animals and humans and there is overwhelming evidence supporting the positive effects of environmental complexity on brain structure and function, including the amelioration of abnormal repetitive behavior. Few studies of individuals with autism have attempted to correlate MRI findings and RRB and no attempt has been made to associate RRB and post-mortem tissue findings. The one replicable finding is the association of RRB and caudate volume. This is consistent with studies of other clinical disorders and animal models, reviewed here, which suggest that functional and structural alterations in circuitry that link specific areas of cortex and basal ganglia appear to be crucial for the expression of RRB. Animal models have provided critical information about the neurobiology of repetitive behavior. These models, however useful, have focused on repetitive sensory motor behavior and have inadequately modeled RRB reflecting resistance to change or insistence on sameness. The neurobiological model emphasized in this review posits that repetitive behaviors are associated with neuroadaptations in cortical-basal ganglia pathways arising from the dynamic interplay of genetic and experiential factors. Our own studies point to reduced activity of the indirect basal ganglia pathway being associated with high levels of repetitive behavior in deer mice. These findings, if generalizable, suggest specific therapeutic targets. These, and perhaps other, perturbations to cortical basal ganglia circuitry are mediated by specific molecular mechanisms (e.g., altered gene expression) that result in long-term, experience-dependent neuroadaptations that initiate and maintain repetitive behavior. A great deal more research is needed to uncover such mechanisms. Work in areas such as substance abuse, OCD, Tourette syndrome, Parkinson's disease, and dementias promise to provide findings critical for identifying neurobiological mechanisms relevant to RRB in autism. Moreover, basic research in areas such as birdsong, habit formation, and procedural learning may provide additional, much needed clues. Understanding the pathophysioloy of repetitive behavior will be critical to identifying novel therapeutic targets and strategies for individuals with autism.

\section{References}

1. Lewis MH, Bodfish JW. Repetitive behavior disorders in autism. Ment Retard Dev Disabil Res Rev. 1998;4:80-9.

2. Turner M. Annotation: repetitive behaviour in autism: a review of psychological research. J Child Psychol Psychiatry. 1999;40 (6):839-49.

3. Rutter M. Diagnosis and definitions of childhood autism. J Autism Child Schizophrenia. 1978;8(2):139-61.

4. Cuccaro ML, Shao Y, Grubber J, Slifer M, Wolpert CM, Donnelly SL, et al. Factor analysis of restricted and repetitive behaviors in autism using the Autism Diagnostic Interview-R. Child Psychiatry Hum Dev. 2003;34(1):3-17.

5. Szatmari P, Georgiades S, Bryson S, Zwaigenbaum L, Roberts $\mathrm{W}$, Mahoney W, et al. Investigating the structure of the restricted, repetitive behaviours and interests domain of autism. J Child Psychol Psychiatry. 2006;47(6):582-90.

6. Georgiades S, Szatmari P, Zwaigenbaum L, Duku E, Bryson S, Roberts W, et al. Structure of the autism symptom phenotype: A proposed multidimensional model. J Am Acad Child Adolesc Psychiatry. 2007;46(2):188-96.

7. Lam KS, Bodfish JW, Piven J. Evidence for three subtypes of repetitive behavior in autism that differ in familiality and association with other symptoms. J Child Psychol Psychiatry. 2008;49(11):1193-200.

8. Bodfish JW, Symons FJ, Parker DE, Lewis MH. Varieties of repetitive behavior in autism: comparisons to mental retardation. J Autism Dev Disord. 2000;30(3):237-43.

9. Frith DD, Done DJ. Stereotyped behaviour in madness and in health. In: Cooper SJ, Dourish CT, editors. Neurobiology of stereotyped behaviour. Clarendon: Oxford; 1990. p. 232-59.

10. Nyatsanza S, Shetty T, Gregory C, Lough S, Dawson K, Hodges JR. A study of stereotypic behaviours in Alzheimer's disease and 
frontal and temporal variant frontotemporal dementia. J Neurol Neurosurg Psychiatry. 2003;74(10):1398-402.

11. Tracy JI, De Leon J, Doonan R, Musciente J, Ballas T, Josiassen RC. Clock drawing in schizophrenia. Psychol Rep. 1996;79(3 Pt 1):923-8.

12. Shigenobu K, Ikeda M, Fukuhara R, Maki N, Hokoishi K, Nebu $\mathrm{A}$, et al. The stereotypy rating inventory for frontotemporal lobar degeneration. Psychiatry Res. 2002;110(2):175-87.

13. Fazzi E, Lanners J, Danova S, Ferrarri-Ginevra O, Gheza C, Luparia A, et al. Stereotyped behaviours in blind children. Brain Develop. 1999;21(8):522-8.

14. Carlson M, Earls F. Psychological and neuroendocrinological sequelae of early social deprivation in institutionalized children in Romania. Ann N Y Acad Sci. 1997;807:419-28.

15. Fisher L, Ames EW, Chisholm K, Savoie L. Problems reported by parents of Romanian orphans adopted to British Columbia. Int J Behav Dev. 1997;20:67-82.

16. Thelen E. Determinants of amounts of stereotyped behavior in normal human infants. Ethol Sociobiol. 1980;1:141-50.

17. Evans DW, Leckman JF, Carter A, Reznick JS, Henshaw D, King RA, et al. Ritual, habit, and perfectionism: the prevalence and development of compulsive-like behavior in normal young children. Child Dev. 1997;68(1):58-68.

18. Leekam S, Tandos J, McConachie H, Meins E, Parkinson K, Wright $\mathrm{C}$, et al. Repetitive behaviours in typically developing 2-year-olds. J Child Psychol Psychiatry. 2007;48(11):11318.

19. Thelen E. Rhythmical stereotypies in normal human infants. Anim Behav. 1979;27(Pt 3):699-715.

20. DeLoache JS, Simcock G, Macari S. Planes, trains, automobilesand tea sets: extremely intense interests in very young children. Dev Psychol. 2007;43(6): 1579-86.

21. Symons FJ, Sperry LA, Dropik PL, Bodfish JW. The early development of stereotypy and self-injury: a review of research methods. J Intellect Disabil Res. 2005;49(Pt 2):144-58.

22. Watt N, Wetherby AM, Barber A, Morgan L. Repetitive and stereotyped behaviors in children with autism spectrum disorders in the second year of life. J Autism Dev Disord. 2008 Feb 12.

23. Freeman BJ, Ritvo ER, Schroth PC, Tonick I, Gurhrie D, Wake L. Behavioral characteristics of high-and-low-IQ autistic children. Am J Psychiatry. 1981;138:25-9.

24. Hermelin B, O'Connor N. The response of self-generated behaviour of severely disturbed children and severely subnormal controls. Br J Soc Clin Psychol. 1963;2:37-43.

25. Lord C. Follow-up of two-year-olds referred for possible autism. J Child Psychol Psychiatry. 1995;36(8):1365-82.

26. Lord C, Pickles A. Language level and nonverbal socialcommunicative behaviors in autistic and language-delayed children. J Am Acad Child Adolesc Psychiatry. 1996;35 (11):1542-50.

27. Szatmari P, Bartolucci G, Bremner R. Asperger's syndrome and autism: comparison of early history and outcome. Dev Med Child Neurol. 1989;31(6):709-20.

28. McDougle CJ, Kresch LE, Goodman WK, Naylor ST, et al. A case-controlled study of repetitive thoughts and behavior in adults with autistic disorder and obsessive-compulsive disorder. Am J Psychiatry. 1995;152(5):772-7.

29. Russell AJ, Mataix-Cols D, Anson M, Murphy DG. Obsessions and compulsions in Asperger syndrome and high-functioning autism. Br J Psychiatry. 2005;186:525-8.

30. Bartak L, Rutter M. Differences between mentally retarded and normally intelligent autistic children. J Autism Child Schizophrenia. 1976;6(2):109-20.

31. Wing L, Gould J. Severe impairments of social interaction and associated abnormalities in children: epidemiology and classification. J Autism Dev Disord. 1979;9(1):11-29.
32. Turner M. Towards an executive dysfunction account of repetitive behaviour in autism. In: Russell J, editor. Autism as an executive disorder. New York: Oxford University Press; 1997. p. $57-100$.

33. O'Hearn K, Asato M, Ordaz S, Luna B. Neurodevelopment and executive function in autism. Dev Psychopathol. 2008;20 (4):1103-32.

34. Ozonoff S, Pennington BF, Rogers SJ. Executive function deficits in high-functioning autistic individuals: relationship to theory of mind. J Child Psychol Psychiatry. 1991;32(7):1081105.

35. Ozonoff S, Strayer DL. Inhibitory function in nonretarded children with autism. J Autism Dev Disord. 1997;27(1):59-77.

36. Lopez BR, Lincoln AJ, Ozonoff S, Lai Z. Examining the relationship between executive functions and restricted, repetitive symptoms of Autistic Disorder. J Autism Dev Disord. 2005;35 (4):445-60.

37. Evans DW, Lewis MD, Iobst E. The role of the orbitofrontal cortex in normally developing compulsive-like behaviors and obsessive-compulsive disorder. Brain Cogn. 2004;55(1):220-34.

38. South M, Ozonoff S, McMahon WM. Repetitive behavior profiles in Asperger syndrome and high-functioning autism. J Autism Dev Disord. 2005;35(2):145-58.

39. Joseph RM, Tager-Flusberg H. The relationship of theory of mind and executive functions to symptom type and severity in children with autism. Dev Psychopathol. 2004;16(1):137-55.

40. Geurts HM, Corbett B, Solomon M. The paradox of cognitive flexibility in autism. Trends Cogn Sci. 2009;13(2):74-82.

41. Evans DW, Elliott JM, Packard MG. Visual organization and perceptual closure are related to compulsive-like behavior in typically developing children. Merrill-Palmer Q. 2001;47 (3):323-35.

42. Chen YH, Rodgers J, McConachie H. Restricted and repetitive behaviours, sensory processing and cognitive style in children with autism spectrum disorders. J Autism Dev Disord. 2008 Nov 18.

43. South M, Ozonoff S, McMahon WM. The relationship between executive functioning, central coherence, and repetitive behaviors in the high-functioning autism spectrum. Autism. 2007;11 (5):437-51.

44. Lovaas I, Newsom C, Hickman C. Self-stimulatory behavior and perceptual reinforcement. J Appl Behav Anal. 1987;20(1):45-68.

45. Minshew NJ, Goldstein G. Autism as a disorder of complex information processing. Ment Retard Dev Disabil Res Rev. 1998;4:129-36.

46. Gabriels RL, Agnewa JA, Miller LJ, Gralla J, Pan Z, Goldson E, et al. Is there a relationship between restricted, repetitive, stereotyped behaviors and interests and abnormal sensory response in children with autism spectrum disorders? Res Autism Spectr Disord. 2008;2:660-70.

47. Rogers SJ, Ozonoff S. Annotation: what do we know about sensory dysfunction in autism? A critical review of the empirical evidence. J Child Psychol Psychiatry. 2005;46(12):1255-68.

48. Bauman ML. Motor dysfunction in autism. In: Joseph AB, Young RR, editors. Movement disorders in neurology and psychiatry. Boston: Blackwell; 1992. p. 660-3.

49. Hallett M, Lebiedowska MK, Thomas SL, Stanhope SJ, Denckla MB, Rumsey J. Locomotion of autistic adults. Arch Neurol. 1993;50(12):1304-8.

50. Jones V, Prior M. Motor imitation abilities and neurological signs in autistic children. J Autism Dev Disord. 1985;15(1):37-46.

51. Kohen-Raz R, Volkmar FR, Cohen DJ. Postural control in children with autism. J Autism Dev Disord. 1992;22(3):419-32.

52. Molloy CA, Dietrich KN, Bhattacharya A. Postural stability in children with autism spectrum disorder. J Autism Dev Disord. 2003;33(6):643-52. 
53. Rogers SJ, Bennetto L, McEvoy R, Pennington BF. Imitation and pantomime in high-functioning adolescents with autism spectrum disorders. Child Dev. 1996;67(5):2060-73.

54. Vilensky JA, Damasio AR, Maurer RG. Gait disturbances in patients with autistic behavior: a preliminary study. Arch Neurol. 1981;38(10):646-9.

55. Segawa M, Nomura Y. Pathophysiology of human locomotion: studies on clinical cases. In: Shimamura M, Grillner S, Edgerton VR, editors. Neurobiological basis of human locomotion. Tokyo, Japan: Japan Scientific Societies; 1991. p. 317-28.

56. Teitelbaum P, Teitelbaum O, Nye J, Fryman J, Maurer RG. Movement analysis in infancy may be useful for early diagnosis of autism. Proc Natl Acad Sci USA. 1998;95(23):13982-7.

57. Bodfish JW, Parker DE, Lewis MH, Sprague RL, Newell KM. Stereotypy and motor control: differences in the postural stability dynamics of persons with stereotyped and dyskinetic movement disorders. Am J Ment Retard. 2001;106(2):123-34.

58. Steffenburg S, Gillberg C, Hellgren L, Andersson L, Gillberg IC, Jakobsson G, et al. A twin study of autism in Denmark, Finland, Iceland, Norway and Sweden. J Child Psychol Psychiatry. 1989;30(3):405-16.

59. Bailey A, Le Couteur A, Gottesman I, Bolton P, Simonoff E, Yuzda E, et al. Autism as a strongly genetic disorder: evidence from a British twin study. Psychol Med. 1995;25(1):63-77.

60. Jorde LB, Hasstedt SJ, Ritvo ER, Mason-Brothers A, Freeman BJ, Pingree C, et al. Complex segregation analysis of autism. Am J Hum Genet. 1991;49(5):932-8.

61. Pickles A, Bolton P, Macdonald H, Bailey A, Le Couteur A, Sim $\mathrm{CH}$, et al. Latent-class analysis of recurrence risks for complex phenotypes with selection and measurement error: a twin and family history study of autism. Am J Hum Genet. 1995;57 (3):717-26.

62. Folstein SE, Rosen-Sheidley B. Genetics of autism: complex aetiology for a heterogeneous disorder. Nat Rev Genet. 2001;2 (12):943-55

63. Risch N, Spiker D, Lotspeich L, Nouri N, Hinds D, Hallmayer J, et al. A genomic screen of autism: evidence for a multilocus etiology. Am J Hum Genet. 1999;65(2):493-507.

64. Buxbaum JD, Silverman JM, Smith CJ, Kilifarski M, Reichert J, Hollander E, et al. Evidence for a susceptibility gene for autism on chromosome 2 and for genetic heterogeneity. Am J Hum Genet. 2001;68(6):1514-20.

65. Shao Y, Raiford KL, Wolpert CM, Cope HA, Ravan SA, AshleyKoch AA, et al. Phenotypic homogeneity provides increased support for linkage on chromosome 2 in autistic disorder. Am J Hum Genet. 2002;70(4):1058-61.

66. Mandy WP, Skuse DH. Research review: What is the association between the social-communication element of autism and repetitive interests, behaviours and activities? J Child Psychol Psychiatry. 2008;49(8):795-808.

67. Ronald A, Happe F, Bolton P, Butcher LM, Price TS, Wheelwright $S$, et al. Genetic heterogeneity between the three components of the autism spectrum: a twin study. J Am Acad Child Adolesc Psychiatry. 2006;45(6):691-9.

68. Silverman JM, Smith CJ, Schmeidler J, Hollander E, Lawlor BA, Fitzgerald $M$, et al. Symptom domains in autism and related conditions: evidence for familiality. Am J Med Genet. 2002;114 (1):64-73.

69. Alsobrook IJ, Leckman JF, Goodman WK, Rasmussen SA, Pauls DL. Segregation analysis of obsessive-compulsive disorder using symptom-based factor scores. Am J Med Genet. 1999;88 (6):669-75.

70. Shao Y, Cuccaro ML, Hauser ER, Raiford KL, Menold MM, Wolpert CM, et al. Fine mapping of autistic disorder to chromosome $15 \mathrm{q} 11-\mathrm{q} 13$ by use of phenotypic subtypes. Am J Hum Genet. 2003;72(3):539-48.
71. Brune CW, Kim SJ, Salt J, Leventhal BL, Lord C, Cook EH Jr. 5-HTTLPR genotype-specific phenotype in children and adolescents with autism. Am J Psychiatry. 2006;163(12):2148-56.

72. Cook EH Jr, Lindgren V, Leventhal BL, Courchesne R, Lincoln A, Shulman C, et al. Autism or atypical autism in maternally but not paternally derived proximal $15 \mathrm{q}$ duplication. Am J Hum Genet. 1997;60(4):928-34.

73. Wolpert C, Pericak-Vance MA, Abramson RK, Wright HH, Cuccaro ML. Autistic symptoms among children and young adults with isodicentric chromosome 15. Am J Med Genet. 2000;96(1):128-9.

74. Wolpert CM, Menold MM, Bass MP, Qumsiyeh MB, Donnelly SL, Ravan SA, et al. Three probands with autistic disorder and isodicentric chromosome 15. Am J Med Genet. 2000;96(3):365-72.

75. Gillberg C. Chromosomal disorders and autism. J Autism Dev Disord. 1998;28(5):415-25.

76. Schroer RJ, Phelan MC, Michaelis RC, Crawford EC, Skinner SA, Cuccaro M, et al. Autism and maternally derived aberrations of chromosome 15q. Am J Med Genet. 1998;76(4):327-36.

77. Browne CE, Dennis NR, Maher E, Long FL, Nicholson JC, Sillibourne J, et al. Inherited interstitial duplications of proximal 15q: genotype-phenotype correlations. Am J Hum Genet. 1997;61(6):1342-52.

78. Bolton PF, Dennis NR, Browne CE, Thomas NS, Veltman MW, Thompson RJ, et al. The phenotypic manifestations of interstitial duplications of proximal $15 q$ with special reference to the autistic spectrum disorders. Am J Med Genet. 2001;105 (8):675-85.

79. Bolton PF, Veltman MW, Weisblatt E, Holmes JR, Thomas NS, Youings SA, et al. Chromosome 15q11-13 abnormalities and other medical conditions in individuals with autism spectrum disorders. Psychiatr Genet. 2004;14(3):131-7.

80. Szatmari P, Paterson AD, Zwaigenbaum L, Roberts W, Brian J, Liu XQ, et al. Mapping autism risk loci using genetic linkage and chromosomal rearrangements. Nat Genet. 2007;39(3):319-28.

81. Sebat J, Lakshmi B, Malhotra D, Troge J, Lese-Martin C, Walsh $\mathrm{T}$, et al. Strong association of de novo copy number mutations with autism. Science. 2007;316(5823):445-9.

82. Shao Y, Wolpert CM, Raiford KL, Menold MM, Donnelly SL, Ravan SA, et al. Genomic screen and follow-up analysis for autistic disorder. Am J Med Genet. 2002;114(1):99-105.

83. Philippe A, Martinez M, Guilloud-Bataille M, Gillberg C, Rastam M, Sponheim E, et al. Genome-wide scan for autism susceptibility genes. Paris Autism Research International Sibpair Study. Hum Mol Genet. 1999;8(5):805-12.

84. Liu J, Nyholt DR, Magnussen P, Parano E, Pavone P, Geschwind $\mathrm{D}$, et al. A genomewide screen for autism susceptibility loci. Am J Hum Genet. 2001;69(2):327-40.

85. Cook EH Jr, Courchesne RY, Cox NJ, Lord C, Gonen D, Guter $\mathrm{SJ}$, et al. Linkage-disequilibrium mapping of autistic disorder, with 15q11-13 markers. Am J Hum Genet. 1998;62(5):107783.

86. Martin ER, Menold MM, Wolpert CM, Bass MP, Donnelly SL, Ravan SA, et al. Analysis of linkage disequilibrium in gammaaminobutyric acid receptor subunit genes in autistic disorder. Am J Med Genet. 2000;96(1):43-8.

87. Buxbaum JD, Silverman JM, Smith CJ, Greenberg DA, Kilifarski M, Reichert J, et al. Association between a GABRB3 polymorphism and autism. Mol Psychiatry. 2002;7(3):311-6.

88. McCauley JL, Olson LM, Delahanty R, Amin T, Nurmi EL, Organ EL, et al. A linkage disequilibrium map of the 1-Mb $15 \mathrm{q} 12$ GABA(A) receptor subunit cluster and association to autism. Am J Med Genet B Neuropsychiatr Genet. 2004;131(1):51-9.

89. Kim SA, Kim JH, Park M, Cho IH, Yoo HJ. Association of GABRB3 polymorphisms with autism spectrum disorders in Korean trios. Neuropsychobiology. 2007;54(3):160-5. 
90. Curran S, Roberts S, Thomas S, Veltman M, Browne J, Medda $\mathrm{E}$, et al. An association analysis of microsatellite markers across the Prader-Willi/Angelman critical region on chromosome 15 (q11-13) and autism spectrum disorder. Am J Med Genet B Neuropsychiatr Genet. 2005;137(1):25-8.

91. Dykens EM, Cassidy SB, King BH. Maladaptive behavior differences in Prader-Willi syndrome due to paternal deletion versus maternal uniparental disomy. Am J Ment Retard. 1999;104(1):67-77.

92. State MW, Dykens EM. Genetics of childhood disorders: XV. Prader-Willi syndrome: genes, brain, and behavior. J Am Acad Child Adolesc Psychiatry. 2000;39(6):797-800.

93. Bittel DC, Butler MG. Prader-Willi syndrome: clinical genetics, cytogenetics and molecular biology. Expert Rev Mol Med. 2005;7(14):1-20.

94. Dykens E, Shah B. Psychiatric disorders in Prader-Willi syndrome: epidemiology and management. CNS Drugs. 2003;17(3):167-78.

95. Veltman MW, Craig EE, Bolton PF. Autism spectrum disorders in Prader-Willi and Angelman syndromes: a systematic review. Psychiatr Genet. 2005;15(4):243-54.

96. Ma DQ, Whitehead PL, Menold MM, Martin ER, Ashley-Koch $\mathrm{AE}$, Mei $\mathrm{H}$, et al. Identification of significant association and gene-gene interaction of GABA receptor subunit genes in autism. Am J Hum Genet. 2005;77(3):377-88.

97. Collins AL, Ma D, Whitehead PL, Martin ER, Wright HH, Abramson RK, et al. Investigation of autism and GABA receptor subunit genes in multiple ethnic groups. Neurogenetics. 2006;7 (3):167-74.

98. Barnby G, Abbott A, Sykes N, Morris A, Weeks DE, Mott R, et al. Candidate-gene screening and association analysis at the autism-susceptibility locus on chromosome 16p: evidence of association at GRIN2A and ABAT. Am J Hum Genet. 2005;76 (6):950-66.

99. Lewis M, Baumeister A. Stereotyped mannerisms in mentally retarded persons: Animal models and theoretical analyses. In: NR E, editor. International review of research in mental retardation, vol. 11. New York: Academic; 1982. p. 123-61.

100. Sivam SP. GBR-12909-induced self-injurious behavior: role of dopamine. Brain Res. 1995;690(2):259-63.

101. Ernst M, Zametkin AJ, Matochik JA, Pascualvaca D, Jons PH, Hardy K, et al. Presynaptic dopaminergic deficits in LeschNyhan disease. N Engl J Med. 1996;334(24):1568-72.

102. Berridge KC, Aldridge JW, Houchard KR, Zhuang X. Sequential super-stereotypy of an instinctive fixed action pattern in hyperdopaminergic mutant mice: a model of obsessive compulsive disorder and Tourette's. BMC Biol. 2005;3:4.

103. Presti MF, Watson CJ, Kennedy RT, Yang M, Lewis MH. Behavior-related alterations of striatal neurochemistry in a mouse model of stereotyped movement disorder. Pharmacol Biochem Behav. 2004;77(3):501-7.

104. Welch JM, Lu J, Rodriguiz RM, Trotta NC, Peca J, Ding JD, et al. Cortico-striatal synaptic defects and OCD-like behaviours in Sapap3-mutant mice. Nature. 2007;448(7156):894-900.

105. Arnold PD, Sicard T, Burroughs E, Richter MA, Kennedy JL. Glutamate transporter gene SLC1A1 associated with obsessivecompulsive disorder. Arch Gen Psychiatry. 2006;63(7):769-76.

106. Dickel DE, Veenstra-VanderWeele J, Cox NJ, Wu X, Fischer DJ, Van Etten-Lee M, et al. Association testing of the positional and functional candidate gene SLC1A1/EAAC1 in early-onset obsessive-compulsive disorder. Arch Gen Psychiatry. 2006;63 (7): $778-85$.

107. Purcell AE, Jeon OH, Zimmerman AW, Blue ME, Pevsner J. Postmortem brain abnormalities of the glutamate neurotransmitter system in autism. Neurology. 2001;57(9):1618-28.
108. Jamain S, Betancur C, Quach H, Philippe A, Fellous M, Giros B, et al. Linkage and association of the glutamate receptor 6 gene with autism. Mol Psychiatry. 2002;7(3):302-10.

109. Shuang M, Liu J, Jia MX, Yang JZ, Wu SP, Gong XH, et al. Family-based association study between autism and glutamate receptor 6 gene in Chinese Han trios. Am J Med Genet B Neuropsychiatr Genet. 2004;131(1):48-50.

110. Feng J, Schroer R, Yan J, Song W, Yang C, Bockholt A, et al. High frequency of neurexin 1beta signal peptide structural variants in patients with autism. Neurosci Lett. 2006;409 (1): $10-3$.

111. Samuels J, Shugart YY, Grados MA, Willour VL, Bienvenu OJ, Greenberg BD, et al. Significant linkage to compulsive hoarding on chromosome 14 in families with obsessive-compulsive disorder: results from the OCD collaborative genetics study. Am J Psychiatry. 2007;164(3):493-9.

112. Boeckers TM, Kreutz MR, Winter C, Zuschratter W, Smalla KH, Sanmarti-Vila L, et al. Proline-rich synapse-associated protein-1/ cortactin binding protein 1 (ProSAP1/CortBP1) is a PDZ-domain protein highly enriched in the postsynaptic density. J Neurosci. 1999;19(15):6506-18.

113. Durand CM, Betancur C, Boeckers TM, Bockmann J, Chaste P, Fauchereau F, et al. Mutations in the gene encoding the synaptic scaffolding protein SHANK3 are associated with autism spectrum disorders. Nat Genet. 2007;39(1):25-7.

114. IMGSAC. A genomewide screen for autism: strong evidence for linkage to chromosomes 2q, 7q, and 16p. Am J Hum Genet. 2001;69(3):570-81.

115. Sutcliffe JS, Delahanty RJ, Prasad HC, McCauley JL, Han Q, Jiang L, et al. Allelic heterogeneity at the serotonin transporter locus (SLC6A4) confers susceptibility to autism and rigidcompulsive behaviors. Am J Hum Genet. 2005;77(2):265-79.

116. Yonan AL, Alarcon M, Cheng R, Magnusson PK, Spence SJ, Palmer AA, et al. A genomewide screen of 345 families for autism-susceptibility loci. Am J Hum Genet. 2003;73(4):886-97.

117. Di Giovanni G, Di Matteo V, Pierucci M, Benigno A, Esposito E. Serotonin involvement in the basal ganglia pathophysiology: could the 5-HT2C receptor be a new target for therapeutic strategies? Curr Med Chem. 2006;13(25):3069-81.

118. McDougle CJ, Naylor ST, Cohen DJ, Aghajanian GK, Heninger GR, Price LH. Effects of tryptophan depletion in drug-free adults with autistic disorder. Arch Gen Psychiatry. 1996;53(11):9931000 .

119. Hollander E, Novotny S, Allen A, Aronowitz B, Cartwright C, DeCaria $C$. The relationship between repetitive behaviors and growth hormone response to sumatriptan challenge in adult autistic disorder. Neuropsychopharmacology. 2000;22(2):163-7.

120. Moss J, Oliver C, Arron K, Burbidge C, Berg K. The prevalence and phenomenology of repetitive behavior in genetic syndromes. J Autism Dev Disord. 2008 Nov 27.

121. Butler MG. Prader-Willi syndrome: current understanding of cause and diagnosis. Am J Med Genet. 1990;35(3):319-32.

122. Thompson T, Gray DB, editors. Destructive behavior in developmental disabilities: diagnosis and treatment. Thousand Oaks, CA: Sage; 1994.

123. Whitman BY, Accardo P. Emotional symptoms in Prader-Willi syndrome adolescents. Am J Med Genet. 1987;28(4):897-905.

124. Webb T, Whittington J, Clarke D, Boer H, Butler J, Holland A. A study of the influence of different genotypes on the physical and behavioral phenotypes of children and adults ascertained clinically as having PWS. Clin Genet. 2002;62(4):273-81.

125. Veltman MW, Thompson RJ, Roberts SE, Thomas NS, Whittington J, Bolton PF. Prader-Willi syndrome - a study comparing deletion and uniparental disomy cases with reference to autism spectrum disorders. Eur Child Adolesc Psychiatry. 2004;13(1):42-50. 
126. Torrado M, Araoz V, Baialardo E, Abraldes K, Mazza C, Krochik G, et al. Clinical-etiologic correlation in children with Prader-Willi syndrome (PWS): An interdisciplinary study. Am J Med Genet A. 2006 Dec 12.

127. Dykens EM, Leckman JF, Cassidy SB. Obsessions and compulsions in Prader-Willi syndrome. J Child Psychol Psychiatry. 1996;37 (8):995-1002.

128. Williams CA, Angelman H, Clayton-Smith J, Driscoll DJ, Hendrickson JE, Knoll JH, et al. Angelman syndrome: consensus for diagnostic criteria. Angelman Syndrome Foundation. Am J Med Genet. 1995;56(2):237-8.

129. Lossie AC, Whitney MM, Amidon D, Dong HJ, Chen P, Theriaque D, et al. Distinct phenotypes distinguish the molecular classes of Angelman syndrome. J Med Genet. 2001;38(12): 834-45.

130. Clarke DJ, Marston G. Problem behaviors associated with 15q- Angelman syndrome. Am J Ment Retard. 2000;105(1): 25-31.

131. Hagerman RJ, Jackson AW, Levitas A 3rd, Rimland B, Braden M. An analysis of autism in fifty males with the fragile $\mathrm{X}$ syndrome. Am J Med Genet. 1986;23(1-2):359-74.

132. Mazzocco MM, Pulsifer M, Fiumara A, Cocuzza M, Nigro F, Incorpora $\mathrm{G}$, et al. Brief report: autistic behaviors among children with fragile $\mathrm{X}$ or Rett syndrome: implications for the classification of pervasive developmental disorder. J Autism Dev Disord. 1998;28(4):321-8.

133. Ben Zeev Ghidoni B. Rett syndrome. Child Adolesc Psychiatr Clin N Am. 2007;16(3):723-43.

134. Niebuhr E. The Cri du Chat syndrome: epidemiology, cytogenetics, and clinical features. Hum Genet. 1978;44(3):227-75.

135. Cornish KM, Pigram J. Developmental and behavioural characteristics of cri du chat syndrome. Arch Dis Child. 1996;75 (5):448-50.

136. Collins MS, Cornish K. A survey of the prevalence of stereotypy, self-injury and aggression in children and young adults with Cri du Chat syndrome. J Intellect Disabil Res. 2002;46(Pt 2):133-40.

137. Hyman P, Oliver C, Hall S. Self-injurious behavior, self-restraint, and compulsive behaviors in Cornelia de Lange syndrome. Am J Ment Retard. 2002;107(2):146-54.

138. Sarimski K. Communication, social-emotional development and parenting stress in Cornelia-de-Lange syndrome. J Intellect Disabil Res. 1997;41(Pt 1):70-5.

139. Kenworthy L, Park T, Charnas LR. Cognitive and behavioral profile of the oculocerebrorenal syndrome of Lowe. Am J Med Genet. 1993;46(3):297-303.

140. Dykens EM, Smith AC. Distinctiveness and correlates of maladaptive behaviour in children and adolescents with Smith-Magenis syndrome. J Intellect Disabil Res. 1998;42 (Pt 6):481-9.

141. Clarke DJ, Boer H. Problem behaviors associated with deletion Prader-Willi, Smith-Magenis, and cri du chat syndromes. Am J Ment Retard. 1998;103(3):264-71.

142. Dykens EM, Finucane BM, Gayley C. Brief report: cognitive and behavioral profiles in persons with Smith-Magenis syndrome. $\mathrm{J}$ Autism Dev Disord. 1997;27(2):203-11.

143. Amaral DG, Schumann CM, Nordahl CW. Neuroanatomy of autism. Trends Neurosci. 2008;31(3):137-45.

144. Sears LL, Vest C, Mohamed S, Bailey J, Ranson BJ, Piven J. An MRI study of the basal ganglia in autism. Prog Neuropsychopharmacol Biol Psychiatry. 1999;23(4):613-24.

145. Hollander E, Phillips A, Chaplin W, Zagursky K, Novotny S, Wasserman S, et al. A placebo controlled crossover trial of liquid fluoxetine on repetitive behaviors in childhood and adolescent autism. Neuropsychopharmacology. 2005;30(3):582-9.
146. Rojas DC, Peterson E, Winterrowd E, Reite ML, Rogers SJ, Tregellas JR. Regional gray matter volumetric changes in autism associated with social and repetitive behavior symptoms. BMC Psychiatry. 2006;6:56.

147. Pierce K, Courchesne E. Evidence for a cerebellar role in reduced exploration and stereotyped behavior in autism. Biol Psychiatry. 2001;49(8):655-64.

148. Thakkar KN, Polli FE, Joseph RM, Tuch DS, Hadjikhani N, Barton JJ, et al. Response monitoring, repetitive behaviour and anterior cingulate abnormalities in autism spectrum disorders (ASD). Brain. 2008;131(Pt 9):2464-78.

149. Shafritz KM, Dichter GS, Baranek GT, Belger A. The neural circuitry mediating shifts in behavioral response and cognitive set in autism. Biol Psychiatry. 2008;63(10):974-80.

150. Lewis MH, Tanimura Y, Lee LW, Bodfish JW. Animal models of restricted repetitive behavior in autism. Behav Brain Res. 2007;176(1):66-74.

151. Shahbazian M, Young J, Yuva-Paylor L, Spencer C, Antalffy B, Noebels $\mathrm{J}$, et al. Mice with truncated MeCP2 recapitulate many Rett syndrome features and display hyperacetylation of histone H3. Neuron. 2002;35(2):243-54.

152. Moretti P, Bouwknecht JA, Teague R, Paylor R, Zoghbi HY. Abnormalities of social interactions and home-cage behavior in a mouse model of Rett syndrome. Hum Mol Genet. 2005;14 (2):205-20.

153. Homanics GE, DeLorey TM, Firestone LL, Quinlan JJ, Handforth A, Harrison NL, et al. Mice devoid of gammaaminobutyrate type A receptor beta3 subunit have epilepsy, cleft palate, and hypersensitive behavior. Proc Natl Acad Sci USA. 1997;94(8):4143-8.

154. DeLorey TM, Handforth A, Anagnostaras SG, Homanics GE, Minassian BA, Asatourian A, et al. Mice lacking the beta3 subunit of the GABAA receptor have the epilepsy phenotype and many of the behavioral characteristics of Angelman syndrome. J Neurosci. 1998;18(20):8505-14.

155. Dykens EM. Maladaptive and compulsive behavior in Prader-Willi syndrome: new insights from older adults. Am J Ment Retard. 2004;109(2):142-53.

156. Greer JM, Capecchi MR. Hoxb8 is required for normal grooming behavior in mice. Neuron. 2002;33(1):23-34.

157. Ambree O, Touma C, Gortz N, Keyvani K, Paulus W, Palme R, et al. Activity changes and marked stereotypic behavior precede Abeta pathology in TgCRND8 Alzheimer mice. Neurobiol Aging. 2006;27(7):955-64.

158. Turner CA, Presti MF, Newman HA, Bugenhagen P, Crnic L, Lewis MH. Spontaneous stereotypy in an animal model of Down syndrome: Ts65Dn mice. Behav Genet. 2001;31(4):393-400.

159. Hines RM, Wu L, Hines DJ, Steenland H, Mansour S, Dahlhaus $\mathrm{R}$, et al. Synaptic imbalance, stereotypies, and impaired social interactions in mice with altered neuroligin 2 expression. J Neurosci. 2008;28(24):6055-67.

160. Rodier PM, Ingram JL, Tisdale B, Croog VJ. Linking etiologies in humans and animal models: studies of autism. Reprod Toxicol (Elmsford, NY). 1997;11(2-3):417-22.

161. Ingram JL, Peckham SM, Tisdale B, Rodier PM. Prenatal exposure of rats to valproic acid reproduces the cerebellar anomalies associated with autism. Neurotoxicol Teratol. 2000;22(3):319-24.

162. Schneider T, Przewlocki R. Behavioral alterations in rats prenatally exposed to valproic acid: animal model of autism. Neuropsychopharmacology. 2005;30(1):80-9.

163. Schneider T, Turczak J, Przewlocki R. Environmental enrichment reverses behavioral alterations in rats prenatally exposed to valproic Acid: issues for a therapeutic approach in autism. Neuropsychopharmacology. 2006;31(1):36-46. 
164. Hornig M, Weissenbock H, Horscroft N, Lipkin WI. An infection-based model of neurodevelopmental damage. Proc Natl Acad Sci USA. 1999;96(21):12102-7.

165. Bachevalier J, Loveland KA. The orbitofrontal-amygdala circuit and self-regulation of social-emotional behavior in autism. Neurosci Biobehav Rev. 2006;30(1):97-117.

166. Bauman MD, Toscano JE, Babineau BA, Mason WA, Amaral DG. Emergence of stereotypies in juvenile monkeys (Macaca mulatta) with neonatal amygdala or hippocampus lesions. Behav Neurosci. 2008;122(5):1005-15.

167. Lipska BK, Jaskiw GE, Chrapusta S, Karoum F, Weinberger DR. Ibotenic acid lesion of the ventral hippocampus differentially affects dopamine and its metabolites in the nucleus accumbens and prefrontal cortex in the rat. Brain Res. 1992;585(1-2):1-6.

168. Martin LA, Ashwood P, Braunschweig D, Cabanlit M, Van de Water J, Amaral DG. Stereotypies and hyperactivity in rhesus monkeys exposed to $\operatorname{IgG}$ from mothers of children with autism. Brain Behav Immun. 2008;22(6):806-16.

169. Moy SS, Nadler JJ, Poe MD, Nonneman RJ, Young NB, Koller $\mathrm{BH}$, et al. Development of a mouse test for repetitive, restricted behaviors: relevance to autism. Behav Brain Res. 2008;188 (1):178-94.

170. Moy SS, Nadler JJ, Young NB, Nonneman RJ, Segall SK, Andrade GM, et al. Social approach and repetitive behavior in eleven inbred mouse strains. Behav Brain Res. 2008;191(1):118-29.

171. Deacon RM, Thomas CL, Rawlins JN, Morley BJ. A comparison of the behavior of C57BL/6 and C57BL/10 mice. Behav Brain Res. 2007;179(2):239-47.

172. Ernst AM, Smelik PG. Site of action of dopamine and apomorphine on compulsive gnawing behaviour in rats. Experientia. 1966;22(12):837-8.

173. Karler R, Bedingfield JB, Thai DK, Calder LD. The role of the frontal cortex in the mouse in behavioral sensitization to amphetamine. Brain Res. 1997;757(2):228-35.

174. Kiyatkin EA, Rebec GV. Striatal neuronal activity and responsiveness to dopamine and glutamate after selective blockade of D1 and D2 dopamine receptors in freely moving rats. J Neurosci. 1999;19(9):3594-609.

175. Karler R, Calder LD, Thai DK, Bedingfield JB. The role of dopamine in the mouse frontal cortex: a new hypothesis of behavioral sensitization to amphetamine and cocaine. Pharmacol Biochem Behav. 1998;61(4):435-43.

176. Scheel-Kruger J, Arnt J, Braestrup C, Christensen AV, Cools AR, Magelund G. GABA-dopamine interaction in substantia nigra and nucleus accumbens - relevance to behavioral stimulation and stereotyped behavior. Adv Biochem Psychopharmacol. 1978; 19:343-6.

177. Barwick VS, Jones DH, Richter JT, Hicks PB, Young KA. Subthalamic nucleus microinjections of 5-HT2 receptor antagonists suppress stereotypy in rats. NeuroReport. 2000;11(2):267-70.

178. Mason G, Rushen J, editors. Stereotypies in captive animals: fundamentals and implications for welfare. Wallingford: $\mathrm{CAB}$ International; 2006.

179. Wurbel H. Ideal homes? Housing effects on rodent brain and behaviour. Trends Neurosci. 2001;24(4):207-11.

180. Bachmann I, Audige L, Stauffacher M. Risk factors associated with behavioural disorders of crib-biting, weaving and boxwalking in Swiss horses. Equine Vet J. 2003;35(2):158-63.

181. Goodwin D, Davidson HP, Harris P. Foraging enrichment for stabled horses: effects on behaviour and selection. Equine Vet J. 2002;34(7):686-91.

182. Mills DS, Taylor K. Field study of the efficacy of three types of nose net for the treatment of headshaking in horses. Vet Rec. 2003;152(2):41-4.

183. Mason GJ. Age and context affect the stereotypies of caged mink. Behaviour. 1993;1993(127):191-229.
184. Presti MF, Powell SB, Lewis MH. Dissociation between spontaneously emitted and apomorphine-induced stereotypy in Peromyscus maniculatus bairdii. Physiol Behav. 2002;75(3):347-53.

185. Presti MF, Gibney BC, Lewis MH. Effects of intrastriatal administration of selective dopaminergic ligands on spontaneous stereotypy in mice. Physiol Behav . 2004;80(4):433-9.

186. Vandebroek I, Odberg FO. Effect of apomorphine on the conflict-induced jumping stereotypy in bank voles. Pharmacol Biochem Behav. 1997;57(4):863-8.

187. Vandebroek I, Berckmoes V, Odberg FO. Dissociation between MK-801- and captivity-induced stereotypies in bank voles. Psychopharmacology. 1998;137(3):205-14.

188. Colacicco G, Welzl H, Lipp HP, Wurbel H. Attentional set-shifting in mice: modification of a rat paradigm, and evidence for straindependent variation. Behav Brain Res. 2002;132(1):95-102.

189. Garner JP, Mason GJ. Evidence for a relationship between cage stereotypies and behavioural disinhibition in laboratory rodents. Behav Brain Res. 2002;136(1):83-92.

190. Vickery S, Mason GJ. Behavioural persistence in captive bears: a reply to Criswell and Galbreath. Ursus. 2005;16:274-9.

191. Garner JP, Meehan CL, Mench JA. Stereotypies in caged parrots, schizophrenia and autism: evidence for a common mechanism. Behav Brain Res. 2003;145(1-2):125-34.

192. Tanimura Y, Yang MC, Lewis MH. Procedural learning and cognitive flexibility in a mouse model of restricted, repetitive behaviour. Behav Brain Res. 2008;189(2):250-6.

193. Canales JJ, Graybiel AM. A measure of striatal function predicts motor stereotypy. Nat Neurosci. 2000;3(4):377-83.

194. Nakano K, Kayahara T, Tsutsumi T, Ushiro H. Neural circuits and functional organization of the striatum. J Neurol. 2000;247 (Suppl 5):V1-15.

195. White NM, Hiroi N. Preferential localization of self-stimulation sites in striosomes/patches in the rat striatum. Proc Natl Acad Sci USA. 1998;95(11):6486-91.

196. Brown LL, Feldman SM, Smith DM, Cavanaugh JR, Ackermann RF, Graybiel AM. Differential metabolic activity in the striosome and matrix compartments of the rat striatum during natural behaviors. J Neurosci. 2002;22(1):305-14.

197. Levesque M, Parent A. The striatofugal fiber system in primates: a reevaluation of its organization based on single-axon tracing studies. Proc Natl Acad Sci USA. 2005;102(33):11888-93.

198. Gerfen CR. Molecular effects of dopamine on striatl-projection pathways In: Olanow CW, editors. Basal Ganglia, Parkinson's disease and levodopa therapy: a supplement to trends in neuroscience, vol. 23. Elsevier; 2000.

199. Olanow CW, Schapira AH, Roth T. Waking up to sleep episodes in Parkinson's disease. Mov Disord. 2000;15(2):212-5.

200. Steiner H, Gerfen CR. Role of dynorphin and enkephalin in the regulation of striatal output pathways and behavior. Exp Brain Res. 1998;123(1-2):60-76.

201. Wu Y, Richard S, Parent A. The organization of the striatal output system: a single-cell juxtacellular labeling study in the rat. Neurosci Res. 2000;38(1):49-62.

202. Aizman O, Brismar H, Uhlen P, Zettergren E, Levey AI, Forssberg $\mathrm{H}$, et al. Anatomical and physiological evidence for D1 and D2 dopamine receptor colocalization in neostriatal neurons. Nat Neurosci. 2000;3(3):226-30.

203. Turner KC, Frost L, Linsenbardt D, McIlroy JR, Muller RA. Atypically diffuse functional connectivity between caudate nuclei and cerebral cortex in autism. Behav Brain Funct. 2006;2:34.

204. Horwitz B, Rumsey JM, Grady CL, Rapoport SI. The cerebral metabolic landscape in autism. Intercorrelations of regional glucose utilization. Arch Neurol. 1988;45(7):749-55.

205. Kates WR, Lanham DC, Singer HS. Frontal white matter reductions in healthy males with complex stereotypies. Pediatr Neurol. 2005;32(2):109-12. 
206. O’Sullivan RL, Rauch SL, Breiter HC, Grachev ID, Baer L, Kennedy DN, et al. Reduced basal ganglia volumes in trichotillomania measured via morphometric magnetic resonance imaging. Biol Psychiatry. 1997;42(1):39-45.

207. Berardelli A, Curra A, Fabbrini G, Gilio F, Manfredi M. Pathophysiology of tics and Tourette syndrome. J Neurol. 2003;250(7):781-7.

208. Bloch MH, Leckman JF, Zhu H, Peterson BS. Caudate volumes in childhood predict symptom severity in adults with Tourette syndrome. Neurology. 2005;65(8):1253-8.

209. Peterson BS, Skudlarski P, Anderson AW, Zhang H, Gatenby JC, Lacadie $\mathrm{CM}$, et al. A functional magnetic resonance imaging study of tic suppression in Tourette syndrome. Arch Gen Psychiatry. 1998;55(4):326-33.

210. Adler CM, McDonough-Ryan P, Sax KW, Holland SK, Arndt S, Strakowski SM. fMRI of neuronal activation with symptom provocation in unmedicated patients with obsessive compulsive disorder. J Psychiatr Res. 2000;34(4-5):317-24.

211. Denys D, van der Wee N, Janssen J, De Geus F, Westenberg HG. Low level of dopaminergic D2 receptor binding in obsessivecompulsive disorder. Biol Psychiatry. 2004;55(10):1041-5.

212. Lewis MH, Gluck JP, Beauchamp AJ, Keresztury MF, Mailman RB. Long-term effects of early social isolation in Macaca mulatta: changes in dopamine receptor function following apomorphine challenge. Brain Res. 1990;513:67-73.

213. Martin LJ, Spicer DM, Lewis MH, Gluck JP, Cork LC. Social deprivation of infant rhesus monkeys alters the chemoarchitecture of the brain: I. Subcortical regions. J Neurosci. 1991;11(11):3344-58.

214. Grabli D, McCairn K, Hirsch EC, Agid Y, Feger J, Francois C, et al. Behavioural disorders induced by external globus pallidus dysfunction in primates: I. Behavioural study. Brain. 2004;127 (Pt 9):2039-54.

215. Baup N, Grabli D, Karachi C, Mounayar S, Francois C, Yelnik J, et al. High-frequency stimulation of the anterior subthalamic nucleus reduces stereotyped behaviors in primates. J Neurosci. 2008;28(35):8785-8.

216. Winter C, Mundt A, Jalali R, Joel D, Harnack D, Morgenstern $\mathrm{R}$, et al. High frequency stimulation and temporary inactivation of the subthalamic nucleus reduce quinpirole-induced compulsive checking behavior in rats. Exp Neurol. 2008;210(1): 217-28.

217. Mallet L, Polosan M, Jaafari N, Baup N, Welter ML, Fontaine D, et al. Subthalamic nucleus stimulation in severe obsessivecompulsive disorder. N Engl J Med. 2008;359(20):2121-34.

218. Lewis MH. Environmental complexity and central nervous system development and function. Ment Retard Dev Disabil Res Rev. 2004;10(2):91-5.

219. Presti MF, Mikes HM, Lewis MH. Selective blockade of spontaneous motor stereotypy via intrastriatal pharmacological manipulation. Pharmacol Biochem Behav. 2003;74(4):833-9.

220. Presti MF, Lewis MH. Striatal opioid peptide content in an animal model of spontaneous stereotypic behavior. Behav Brain Res. 2005;157(2):363-8.

221. Tanimura Y, Williams D, Lewis MH. Striatopallidal pathyway activation and spontaneous stereotypy in an animal model of restricted repetitive behavior. Soc. Neurosci. 2008.

222. Graybiel AM. Habits, rituals, and the evaluative brain. Annu Rev Neurosci. 2008;31:359-87.
223. Nelson A, Killcross S. Amphetamine exposure enhances habit formation. J Neurosci. 2006;26(14):3805-12.

224. Canales JJ, Graybiel AM. Patterns of gene expression and behavior induced by chronic dopamine treatments. Ann Neurol. 2000;47(4 Suppl 1):S53-9.

225. Olveczky BP, Andalman AS, Fee MS. Vocal experimentation in the juvenile songbird requires a basal ganglia circuit. PLoS Biol. 2005;3(5):e153.

226. Nestler EJ, Barrot M, Self DW. DeltaFosB: a sustained molecular switch for addiction. Proc Natl Acad Sci USA. 2001;98(20):11042-6.

227. Nestler EJ, Kelz MB, Chen J. DeltaFosB: a molecular mediator of long-term neural and behavioral plasticity. Brain Res. 1999;835(1):10-7.

228. Chen J, Kelz MB, Hope BT, Nakabeppu Y, Nestler EJ. Chronic Fos-related antigens: stable variants of deltaFosB induced in brain by chronic treatments. J Neurosci. 1997;17(13):4933-41.

229. Kelz MB, Chen J, Carlezon WA Jr, Whisler K, Gilden L, Beckmann AM, et al. Expression of the transcription factor deltaFosB in the brain controls sensitivity to cocaine. Nature. 1999;401(6750):272-6.

230. Bibb JA, Nishi A, O'Callaghan JP, Ule J, Lan M, Snyder GL, et al. Phosphorylation of protein phosphatase inhibitor-1 by Cdk5. J Biol Chem. 2001;276(17):14490-7.

231. McClung CA, Ulery PG, Perrotti LI, Zachariou V, Berton O, Nestler EJ. DeltaFosB: a molecular switch for long-term adaptation in the brain. Brain Res Mol Brain Res. 2004;132 (2): $146-54$.

232. Cenci MA, Tranberg A, Andersson M, Hilbertson A. Changes in the regional and compartmental distribution of FosB- and JunBlike immunoreactivity induced in the dopamine-denervated rat striatum by acute or chronic L-dopa treatment. Neuroscience. 1999;94(2):515-27.

233. Andersson M, Hilbertson A, Cenci MA. Striatal fosB expression is causally linked with 1-DOPA-induced abnormal involuntary movements and the associated upregulation of striatal prodynorphin mRNA in a rat model of Parkinson's disease. Neurobiol Dis. 1999;6 (6):461-74.

234. Doucet JP, Nakabeppu Y, Bedard PJ, Hope BT, Nestler EJ, Jasmin BJ, et al. Chronic alterations in dopaminergic neurotransmission produce a persistent elevation of deltaFosB-like protein(s) in both the rodent and primate striatum. Eur J NeuroSci. 1996;8(2):365-81.

235. Santini E, Alcacer C, Cacciatore S, Heiman M, Herve D, Greengard $\mathrm{P}$, et al. L-DOPA activates ERK signaling and phosphorylates histone $\mathrm{H} 3$ in the striatonigral medium spiny neurons of hemiparkinsonian mice. J Neurochem. 2009;108(3):621-33.

236. Werme M, Messer C, Olson L, Gilden L, Thoren P, Nestler EJ, et al. Delta FosB regulates wheel running. J Neurosci. 2002;22 (18):8133-8.

237. Saka E, Goodrich C, Harlan P, Madras BK, Graybiel AM. Repetitive behaviors in monkeys are linked to specific striatal activation patterns. J Neurosci. 2004;24(34):7557-65.

238. Graybiel AM, Canales JJ, Capper-Loup C. Levodopa-induced dyskinesias and dopamine-dependent stereotypies: a new hypothesis [In Proces Citation]. Trends Neurosci. 2000;23:S71-7.

239. Esbensen AJ, Seltzer MM, Lam KS, Bodfish JW. Age-Related Differences in Restricted Repetitive Behaviors in Autism Spectrum Disorders. J Autism Dev Disord. 2008 Jun 20. 